\title{
Measuring the Environmental Benefits of Wind-Generated Electricity
}

\author{
Joseph A. Cullen
}

December 2010

\begin{abstract}
Production subsidies for renewable energy, such as solar or wind power, are rationalized due to their perceived environmental benefits. Subsidizing these projects allows clean, renewable technologies to produce electricity that would otherwise have been produced by dirtier, fossil-fuel power plants. Wind energy, in particular, has taken advantage of subsidies over the past decade to capture the largest share of all renewable power technologies. However, little empirical research has been conducted which would quantify the environmental benefits of wind power. In this paper, I quantify the emissions offset by wind power for a large electricity grid in Texas using observed production behavior. By exploiting the randomness inherent in wind, I can identify generator level patterns of substitution between wind-generated electricity and conventionally-generated electricity to measure offset emissions. For plausible social costs of pollution, I find that the value of emissions offset by wind power are greater than the renewable energy subsidies used to induce investment in wind farms.
\end{abstract}




\section{Introduction}

Wind energy has experienced dramatic growth over the past decade, due to declining production costs and generous government subsidies. These politically popular subsidies provide a significant stream of revenue for renewable energy operations, sometimes providing half of the revenues for a wind farm. Subsidies of wind power are said to be justified by the environmental benefits of wind-generated electricity because wind power produces none of the pollutants common to conventional generators, such as carbon dioxide $\left(\mathrm{CO}_{2}\right)$, nitrous oxides $\left(\mathrm{NO}_{\mathrm{x}}\right)$, and sulfure dioxide $\left(\mathrm{SO}_{2}\right)$. Given the lack of national climate legislation, renewable subsidies are likely to be an important policy instrument for carbon mitigation for some time. In this paper, I compare the environmental benefits that stem from wind power production, with the stream of subsidies given to stimulate wind farm power production.

Since electricity produced by wind is emission-free, the development of wind power may reduce aggregate pollution by offsetting production from fossil-fuel generated electricity production. When low marginal cost wind-generated electricity enters the grid, higher marginal cost fossil fuel generators will reduce their output. However, emission rates of fossil fuel generators vary greatly by the type and age of the generator. Thus, the quantity of emissions offset by wind power will depend crucially on which generators reduce their output. To date, no studies have attempted to empirically measure the environmental contribution of wind power resulting from these production offsets.

Utilizing information on production decisions in 15-minute intervals on the Texas electricity grid, I estimate the response of each generator to exogenous changes in wind power, using a reduced form model. Realizing that wind power production is not 
completely random, I control for factors that may drive the incentives for electricity

production, which may also be correlated with wind power production. The resulting quasi-experimental residual variation is then used to identify a substitution coefficient for each generator on the grid. This measures the average reduction in output due to a 1 megawatt (MW) increase in wind energy production. These production offsets translate directly into emissions offset using EPA measurements of power plant emission rates.

Estimated emission offsets can be valued by appealing to pollution permit markets for regulated pollutants $\left(\mathrm{NO}_{\mathrm{x}}\right.$ and $\left.\mathrm{SO}_{2}\right)$ and estimates from the literature on the social cost of carbon for unregulated $\mathrm{CO}_{2}$ emissions. This allows a direct comparison between the value of offset emissions with the cost of subsidies which drive investment in wind farms.

The remainder of the paper proceeds as follows. First, I describe the nature of federal and state subsidies received by wind power. Then I discuss the production of wind power and the institutions of the electricity market. This is followed by a description of the data, model, and estimation method. In the final section, I present the results and determine the value of offset emissions before concluding.

\section{Wind Power Subsidies}

Over the past decade, installed wind power production capacity has displayed explosive growth. As shown in Figure 1, installed wind capacity more than doubled between 2004 and 2007, increasing from $6729 \mathrm{MW}$ to 16,847 MW (AWEA 2008). By the end of 2010, wind capacity in the U.S. will total over 36,000 MW(AWEA 2010). In 2007, wind power ranked second in newly installed capacity in the US, after natural gas burning power 
plants $^{1}$. In 2008 and 2009, net capacity additions of wind power outpaced the net capacity additions of all other generator types combined ${ }^{2}$. Although wind power represents a small fraction of total generating capacity nationwide, it is on track to have capacity shares upwards of $10 \%$ in some regional electricity markets (ERCOT 2007).

1 Estimated new capacity installed in 2007 by type: Gas 9800 MW, Wind 5244 MW, Coal 1600 MW, Petroleum 255 MW (EIA 2008)

2 Annual net capacity additions are defined as the difference in installed electricity generating capacity year-to-year. The net capacity addition for each generator type includes new capacity built, and old capacity which is retired. The net capacity additions for the major fuel types in 2008 are: Wind $8386 \mathrm{MW}$, Natural Gas 5220 MW, Coal 1259 MW. The net capacity additions for the major fuel types in 2008 are: Wind 9704 MW, Natural Gas 5154 MW, Coal 1426 MW. Data come from the Energy Information Administration annual report (EIA 2010) 
Figure 1: Cumulative Installed Wind Capacity in the U.S.

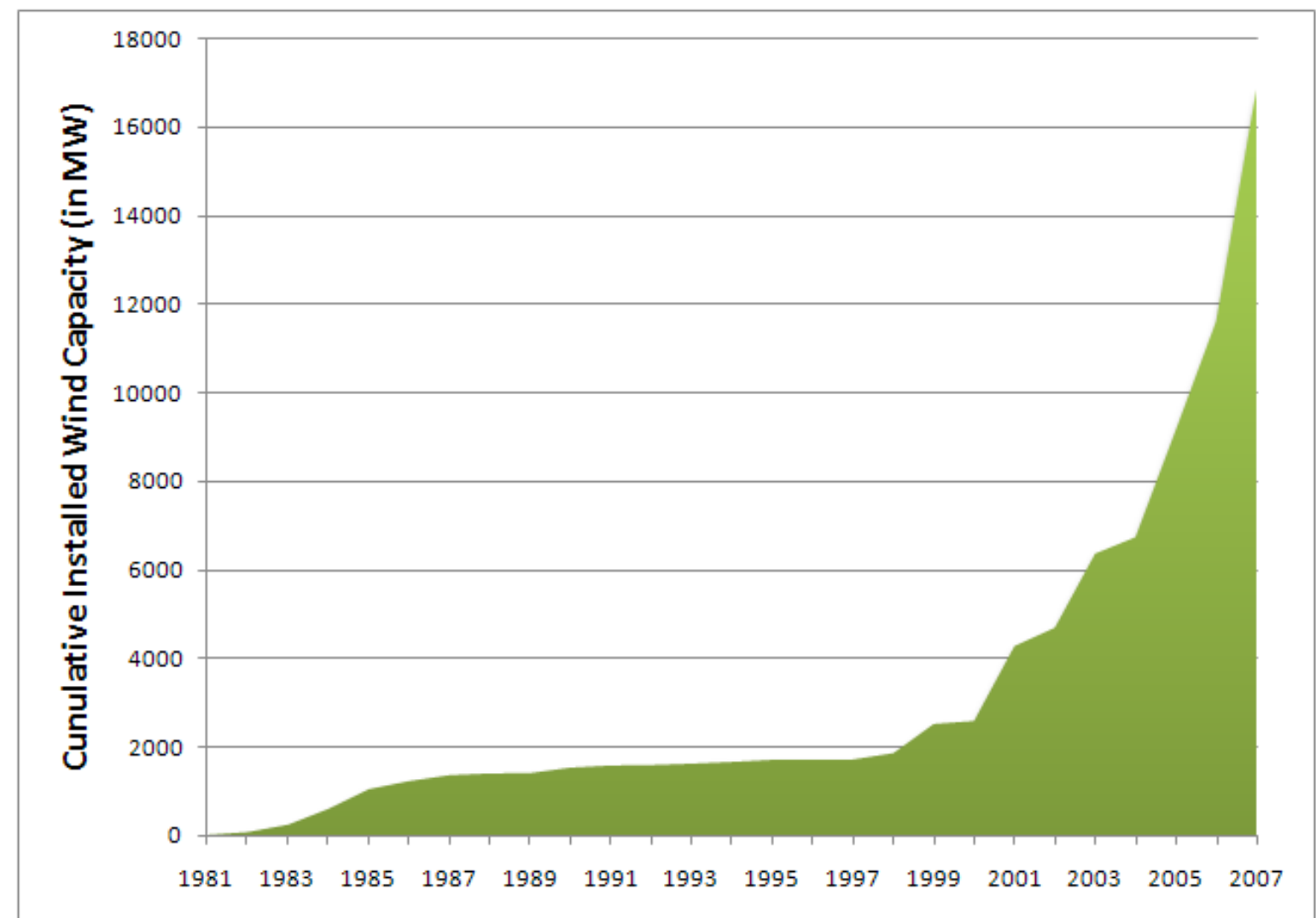

Source: AEWA Wind Database

Two factors have been of significant importance in the growth of wind power. First, technology advancements in wind turbines have reduced the cost of wind power by $80 \%$ over the past 30 years (Wiser and Bolinger 2006). Wind power is characterized by large up front equipment costs and very low operational costs. Better tower design and manufacturing processes have reduced the up-front costs for the same capacity level which lowers the levelized cost of producing wind power. The second important driver of growth has been federal and state programs which subsidize renewable energy. The primary subsidies which support wind energy production are state Renewable Portfolio Standards (RPS) and the federal Production Tax Credit (PTC) ${ }^{3}$.

3 Renewable Portfolio Standards are state-level regulations that require a certain proportion of power in the state to be derived from a renewable source. Typically, each electricity provider has to produce the 
Both the federal PTC and state RPSs are output-based subsidies rather than investment subsidies. The financial benefits of RPS credits vary greatly by state, ranging from $\$ 5$ MWh to $\$ 50 \mathrm{MWh}$, depending on the specific RPS, the supply of renewable energy credits in the state, and the demand for renewable energy credits outside the state (Wiser and Barbose 2008). The federal production tax credit (PTC) on the other hand guarantees an inflation-adjusted tax credit of $\$ 20 \mathrm{MWh}$ for the first ten years of production from the facility. Since wholesale electricity typically sells for between $\$ 30$ and $\$ 50$ per $M W h$, the PTC alone represents a 40\%-67\% increase in revenue for a wind farm operator. The federal PTC is critical for new wind investment. The importance of the PTC to the industry can be seen by looking at the patterns of wind capacity development. The PTC launched in 1992 and was scheduled to expire in 1999, but has been continued through a series of short one-to-two-year extensions. However, more often than not, the subsidy has expired before it has been renewed by Congress. It has expired three times (at the end of 1999, 2001, and 2003) and was renewed retroactively after a lapse of anywhere from 3-to10 months (AWEA 2008). Since renewal has always included a retroactive extension, there has technically been no gap in the coverage of the PTC. However, investors still risked the possibility of no renewal or a non-retroactive renewal ${ }^{4}$.

required proportion of renewable energy or must buy renewable energy credits from generators that do produce renewable energy. The sale of renewable energy credits is an implicit subsidy to renewable generators such as wind generators.

The federal production tax credit (PTC) guarantees an inflation adjusted tax credit for the first ten years of production of the facility. Given that the owner of the facility has a sufficiently large tax liability, the tax credit is effectively a payment from the government to the wind farm operator. $\}$. Even with the downward trend in costs, it is generally acknowledged that without government subsidies wind farms could not compete with conventional thermal generators which use gas, coal or uranium as fuel (Wiser and Bolinger 2006)

4 This uncertainty has lead to a boom and bust cycle of wind power development. According to industry advocates, six to eight months before the expiration of the PTC, financing for capital dries up as lenders hesitate to finance wind projects due to the uncertainty surrounding renewal of the subsidy. Also since the subsidy guarantees 10 years of payments only to projects completed before its expiration, developers rush to complete projects before the expiration resulting in smaller than planned installations or higher installation costs for wind farms (AWEA 2008). 
In 2000, 2002 and 2004, there was a precipitous drop in installed capacity after the expiration of the PTC in each preceding year (see fig 2). Since the last expiration, there has been a continued rise in annual installations of wind power. While not conclusive, this does underline the importance of the PTC for the continued development and operation of wind farms $s^{5}$

5 It is important to note that Renewable Portfolio Standards (RPS) and the PTC are not independent. Most wind developments have occurred in states with a RPS, indicating that the federal PTC alone may not be sufficient to induce the level of investment observed. On the other hand, many state Renewable Portfolio Standards would have been too costly to implement without the federal production tax credit. Together, though, they have been an effective tool in promoting wind energy 
Figure 2: Annual Installations of Wind Capacity in the U.S.

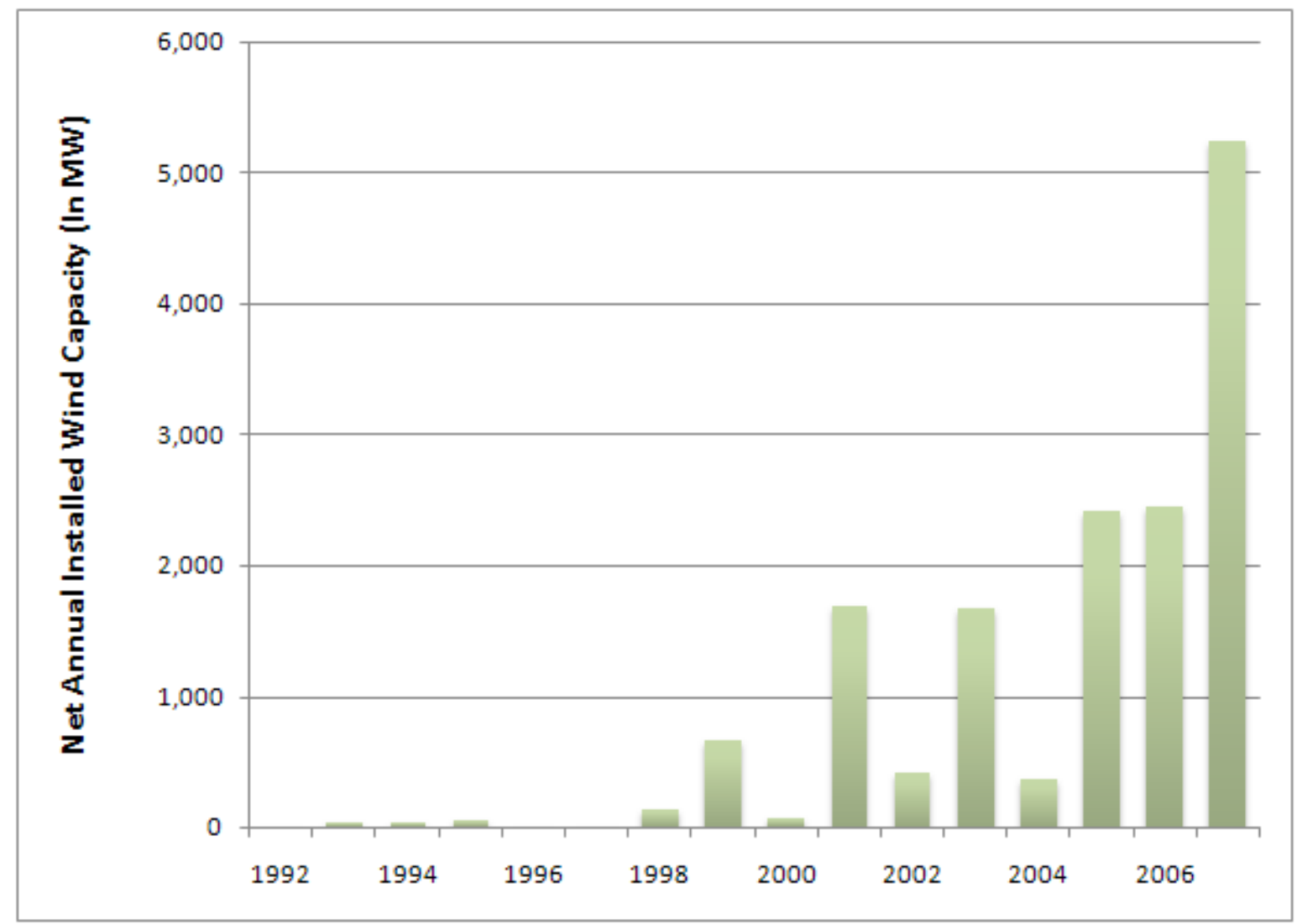

Source: AWEA Wind Database

It is reasonable to assume that without the subsidies, investment in wind farms would have been negligible over the past decade. Throughout this paper I maintain the assumption that federal and state subsidies are responsible for the growth in installed wind capacity over the past ten years.

\section{Generating Substitutes}

Wind generation has attracted subsidies in large part because it is a "green" energy source.

Wind turbines produce none of the environmentally damaging emissions, such as sulfur 
dioxide $\left(\mathrm{SO}_{2}\right)$, carbon dioxide $\left(\mathrm{CO}_{2}\right)$, and nitrous oxides $\left(\mathrm{NO}_{\mathrm{x}}\right)$, typically associated with electricity production ${ }^{6}$. Carbon dioxide emissions in particular are a source of increasing concern due to the role they play in global climate change.

When wind power is introduced into the electricity grid, every MWh of electricity produced by wind turbines "offsets" pollution that otherwise would have been emitted by a conventional, fossil fuel generator ${ }^{7}$. The type and quantity of pollution offset depends crucially on the specific fossil fuel generator whose production is offset. Emissions per MWh of electricity produced vary greatly between electricity generators due to differing fuel types, generator efficiencies, and installed abatement technologies. For instance, comparing the difference in emissions between wind and clean, natural gas generators would show a much smaller impact than the comparison of wind and a relatively "dirty" generator, such as an older coal plant ${ }^{8}$. Thus identifying the generating substitutes of wind power is of first order importance in determining the extent of the environmental impact.

One way to model generating substitutes for wind power is to use a simple marginal cost based approach. With this approach generators are ordered in a production stack, ranging from lowest to highest marginal cost. The production stack is then the market level supply function. This supply function is then used to determine the operating level of each generator for any given level of demand.

6 Although wind power is "green" in the traditional sense, wind farms do create their own negative externalities. Wind farms are often opposed because of the the aesthetic damage they inflict on the landscape or because of noise "pollution"(Ladenburg and Dubgaard 2007). In addition, turbines may disrupt or kill birds or bats in the area (Baerwald et al. 2008; Smallwood and Karas 2009). This paper will not attempt to create a comprehensive cost-benefit analysis, but rather will measure benefits from the emissions offset by wind farms.

7 I use the term "offset" to mean the emissions that would have been produced by conventional generators to replace the electricity produced by wind generators. It does not take into account any potential demand response to electricity price changes induced by wind power production.

8 A high-polluting coal plant emits 4 times $\mathrm{CO}_{2}, 100$ times $\mathrm{SO}_{2}, 15$ times the $\mathrm{NO}_{\mathrm{x}}$ as a newer generator burning natural gas (EPA 2006). 
In this framework, at any given time, all low marginal cost generators are operating at full capacity before any higher marginal cost capacity is brought online. Since wind power is a very low marginal cost supplier, it is inserted near the bottom of the stack and "offsets" production from the highest marginal producers at the top of the stack. This is the same approach used other studies, such as Newcomer, et. al. (2008), to analyze potential impacts of a carbon tax.

Economically, this approach essentially assumes a static equilibrium with perfect competition, no transmission constraints, and perfect foresight. In reality, these conditions are not likely to hold. In particular, generators compete in an uncertain environment with dynamic constraints. Production decisions are dynamic, due to the costs of starting and shutting down generators (startup costs) and constraints on how quickly generators can change output (ramping constraints). This is further complicated by dramatically fluctuating, uncertain electrical demand that varies over the course of a day and by season. Dispatching generators optimally, to meet these demand fluctuations, requires solving a complex, dynamic programming problem due to the intertemporal costs and constraints which face producers . Optimal dispatch typically involves higher marginal cost generators operating when lower marginal cost generators are operating below maximum capacity. Thus, a back-of-the-envelope calculation which would substitute low marginal cost wind power for the highest marginal cost generator currently employed, is not likely to produce satisfactory results. Adding the possibility of market power and transmission constraints casts further doubt on the validity of such a marginal cost stack approach.

Another approach that has been used in the literature relies on proprietary, full-information, grid modeling software. These sophisticated software packages explicitly model the 
dynamic dispatch process using a set of calibrated parameters which characterize the dynamic constraints for each generator. The software then solves a joint optimization problem which deploys generators to meet a known path of demand in a least cost manner.

This engineering approach has been used to assess the impact of exposing the grid to various levels of wind power ${ }^{9}$. It has significant advantages over the marginal cost stack approach, in that it takes into account the operating dynamics facing generators. However, the modeling software requires a wealth of proprietary data on generators and transmission lines which would be unlikely to be available to any entity but the grid manager. It also uses a perfect foresight, cost minimization approach to simulate a hypothetical introduction of wind power which does not allow for uncertainty or market power to affect the results.

In this paper I use an alternative approach for identifying generating substitutes for wind power. Rather than using an engineering or marginal cost stack approach which calculates emission offsets given a set of parameters, I use an econometric approach to estimate the emissions offset by wind power from observed output decisions. My econometric model exploits random and exogenous changes in the output of wind farms to identify the generating substitutes of wind power from observed, rather than simulated, behavior in such a way that allows for a high degree of heterogeneity among generators. I use a flexible, reduced form model which respects the dynamic constraints of generators, incorporates firms' reactions to uncertainty, and admits market power which may exist in certain states of the market. It does not require proprietary data on generators, but relies

9 For example, one study conducted by GE Energy for the New York State Energy Research and Development Authority, simulated the introduction of 3,300 MWh wind capacity ( $10 \%$ of total capacity) into the system (GE 2005). Using load and wind profiles from 2000-2001, researchers projected load, wind power, and conventional generation for the year 2008, using GE's electrical system simulation software. The impetus for this study was the concern that the increased level wind power would adversely affect the reliability of the grid and impose excessive costs on the transmission system, but they also were able to calculate emissions changes due to wind power. 
only on publicly available generator output and characteristics.

However, this econometric approach is not without its own drawbacks. First, since it requires observed behavior, a significant portion of wind power production must exist on a grid in order to estimate its effects. This rules out prospective studies on impact of new wind power capacity on grids where none currently exists, as is common in the engineering literature. Also, since the current approach uses a reduced form model rather than a structural approach, it is not useful for predicting outcomes that are far out of sample. For instance, it might not produce accurate predictions of offset emissions if the amount of installed capacity on the grid were to double from the current observed levels. A full structural model, such as Cullen (2010), or an engineering model would be necessary for simulating outcomes on any grid where installed capacity is significantly different from what is currently observed. Likewise, my econometric approach cannot comment on wind-induced reliability, or congestion issues that engineering approaches are geared to address. However, an econometric approach can provide an estimate of the marginal impact of wind power on the production of other generators, based on observed behavior and current market conditions. This paper contributes to the literature because it is the first to use econometric methods to identify the generating substitutes for wind power and the associated offset emissions.

Given that the generating substitutes for wind power can be estimated, it is straightforward to calculate emission offsets by wind. The Environmental Protection Agency (EPA) monitors emissions from fossil fuel power plants and provides the average annual emissions rates for each power plant in units of pollution per MWh of electricity produced. For a given power plant, multiplying the electricity production offset by the emissions rate 
gives the quantity of emissions offset by wind power. Summing together all the power plants on a grid provides an estimate of the total emissions offset by wind power.

\section{Wind Production}

The exogeneity of wind-generated electricity is an important identifying assumption in this paper and so requires some justification. The output of conventional generators is clearly not exogenous. Most types of generators can adjust their output at will, although the time and cost associated with such adjustments varies. Wind operators, on the other hand, have relatively little control over output since they have no control over their fuel source, the wind. On a calm day, no electricity can be produced. On a windy day, operators can either fully utilize their productive capabilities or curtail their production which is known in the industry as "spilling wind"10. Curtailing production amounts to throwing away free electricity since the marginal cost of fuel is zero and the marginal costs of operation are nearly zero.

In fact, nearly all costs associated with wind power production are incurred during the construction and installation phase of a wind farm. A modern $1 \mathrm{MWh}$ wind turbine costs roughly $\$ 1$ million to construct and install. The only marginal costs facing a wind farm are those related to usage induced maintenance. Overall, operating and maintenance costs are very low compared when with fossil fuel or even nuclear plants (Wiser and Barbose 2008). The high fixed-capital costs and the essentially nonexistent marginal costs of production, create incentives for the wind farm operator to produce as much electricity as possible

10 Spilling wind is achieved by tilting the blades of the turbine so that some of the in "spills" over the blades rather than being fully utilized to propel the turbine. Spilling wind also occurs at very high wind speeds. It allows turbines to operate when the total wind energy available is greater than the capacity of the turbine. 
given the available wind. In fact, a central task for a company operating a wind farm is to monitor turbines in real time to ensure that each turbine is operating on its power curve. A turbine's power curve is the production frontier for the amount of power a turbine should be able to produce at any given wind speed. Keeping on the power curve means that the firm is using its capital assets to their maximum potential.

Subsidies, which are earned for each MWh of output from the wind farm, further incentivize production. With the addition of federal and state output subsidies, the marginal cost of wind power actually becomes negative. That is, a wind farm would find it profitable to produce electricity even if wholesale electricity prices were less than zero. For example, with state and federal subsidies at around \$30/MWh a wind farm would not voluntarily curtail production unless wholesale electricity prices were less than $-\$ 30 / \mathrm{MWh}$. Since such prices are a relatively rare occurrence, wind farms have little incentive to curtail output for economic reasons ${ }^{11}$. Consequently, whenever the wind is blowing, the wind farm will be supplying electricity to the grid ${ }^{12}$. Other generators, which have significant fuel costs, storable fuel, and full control over their output, will reduce output to balance supply and demand on the grid when wind power comes online.

11 Negative wholesale electricity prices occur in $0.19 \%$ of periods over the two-year period of my sample on the grid I am analyzing. Prices below $-\$ 30 / \mathrm{MWh}$ occur only $0.08 \%$ of the time. In addition, there are rare occurrences when wind farms, or conventional generators for that matter, may be required to reduce production, regardless of the price in the market. Generators are sometimes called on to curtail production in emergency situations to ensure the reliability of the grid, or when the generator is causing local transmission congestion patterns that cannot be resolved with price mechanisms. However, like negative prices, these situations do not arise often.

12 These incentives are reflected in power contracts. Wind operators usually sell their output through longterm, 20-year-purchase power agreements (PPAs). Over the length of the contract, the buyer agrees to purchase all power that can be generated by the wind farm. Usually the buyer is specifically interested in the environmental attributes of wind power to fulfill some "green" objective, such as meeting state renewable portfolio standards. These environmental attributes of production are jointly purchased with the electricity in most contracts. Wind operators, on the other hand, keep the federal PTC accruing from electricity production. If the need arises to curtail production to maintain the reliability of the grid or because the buyer requests a lower production, many PPAs still require that the buyer pay the seller for the electricity that could have been produced, but was not. In addition, the buyer may have to compensate the wind operator for forgone federal tax credits due to the lower output (Windustry 2008). 
Although it can be argued that wind power production is exogenous, as output is nearly always determined by the weather, it is not completely random. Wind patterns exhibit systematic seasonal and diurnal fluctuations. For example, on the Texas grid considered in this study, wind power production is high during the winter and spring months and low during the summer and fall. On a daily level, wind power production is higher during the night than during the day. Figure 3 below plots average hourly demand and average hourly wind power production against each other. Figure 4 does the same for seasonal power production. The negative correlation between demand and wind power production is striking and influences the type of generators that will substitute for wind power. In particular, it means that wind power may cut into production from base load generators. In addition these correlations in the data, wind power exhibits significant variation around these averages. It is this quasi-experimental variation, driven by weather fluctuations, that can be used for identifying generating substitutes for wind power in the model. 
Figure 3: Average hourly wind production and electricity demand

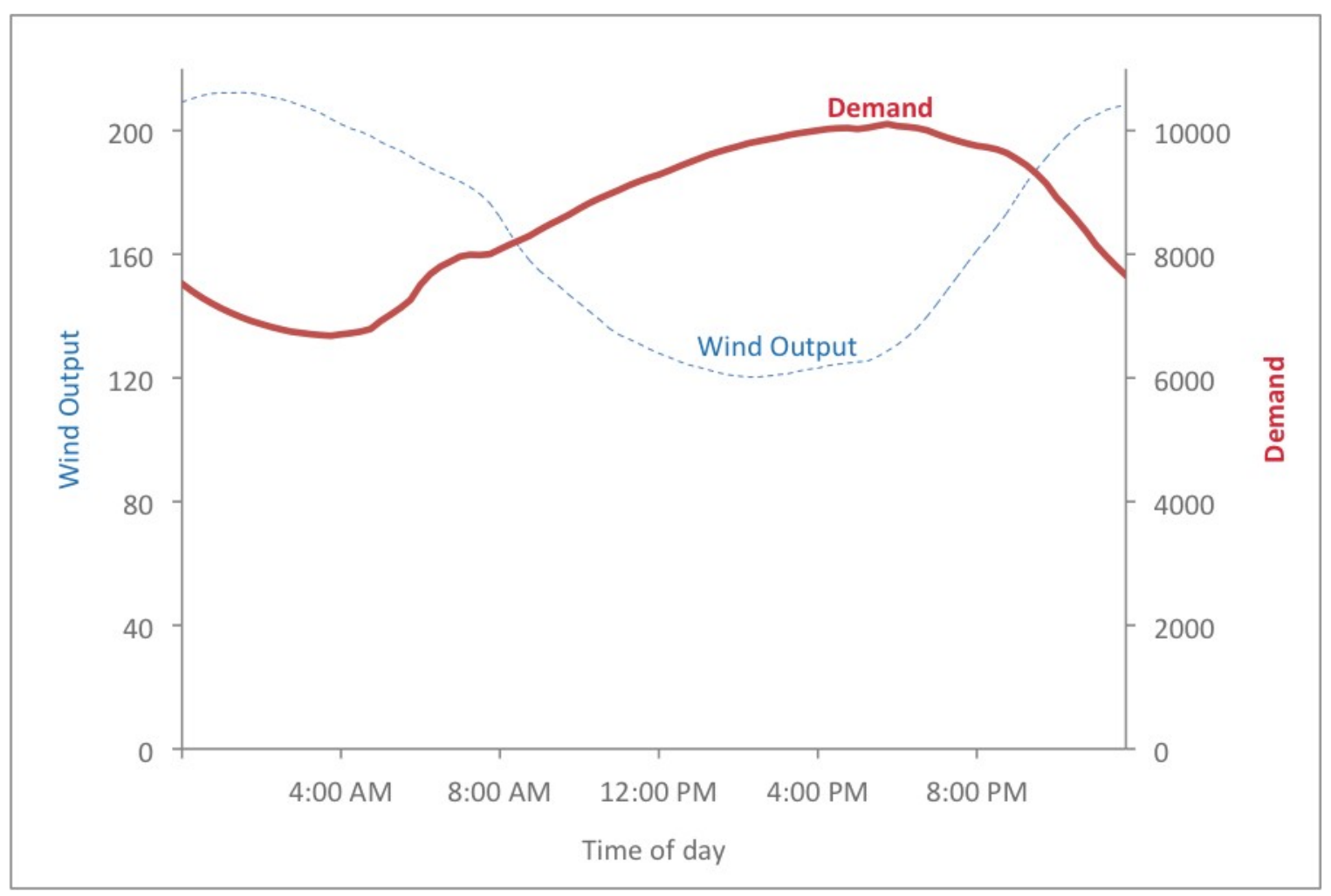

Figure 4: Average monthly wind production and electricity demand

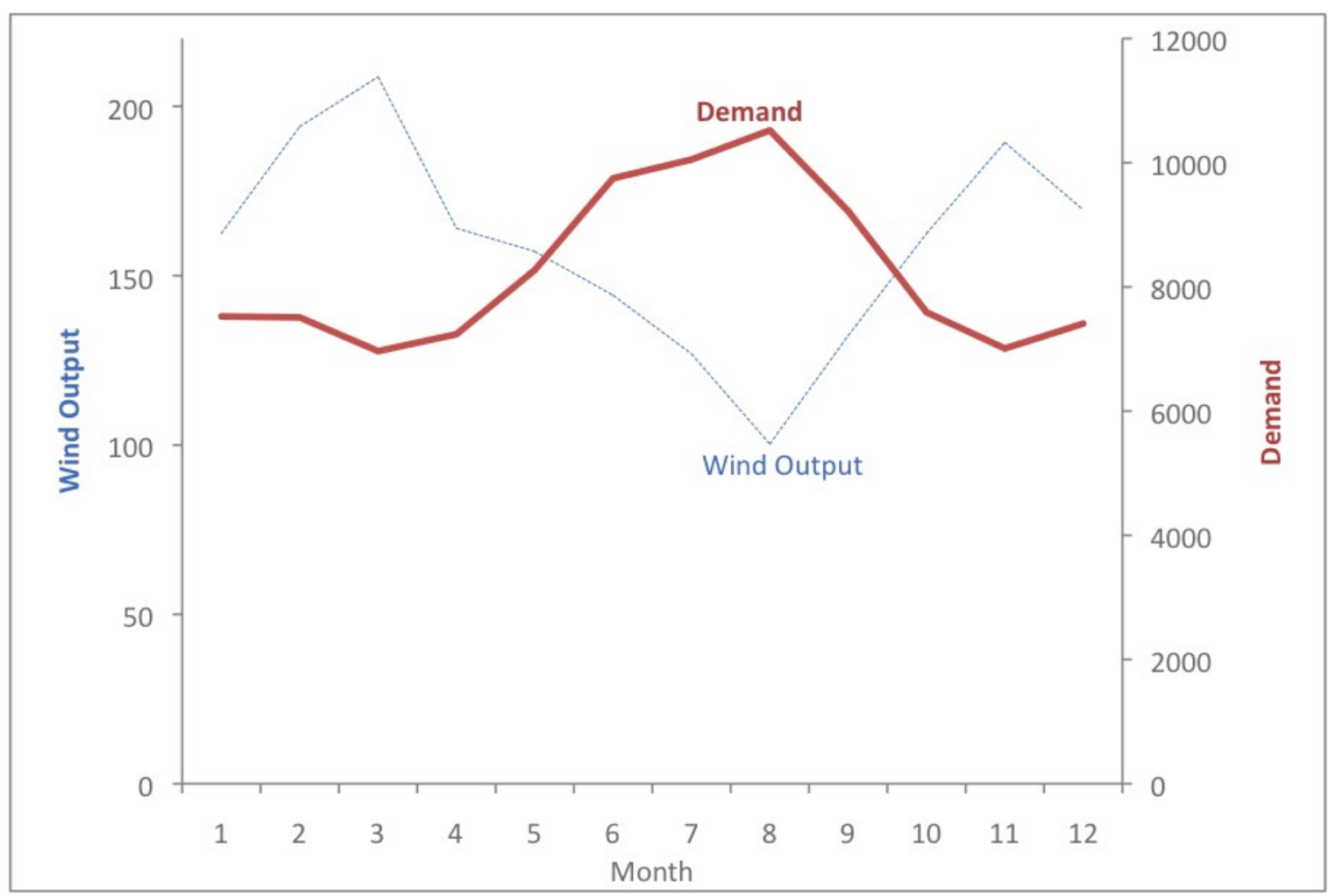




\section{Data}

For the econometric analysis, I focus on a grid managed by the Electricity Reliability

Council of Texas (ERCOT) which serves the majority of the state of Texas. The period of my analysis starts in April of 2005 and continues through April of 2007.

I chose this electric grid for several reasons. First, wind capacity represents a nontrivial share of generating capacity. By the end of the sample, in March of 2007, wind farms account for over $5 \%$ of installed generating capacity on the grid. The market share of electricity generated by wind, at any point in time, ranges from $0 \%$ to $10 \%$ of total electricity consumed. Second, this grid is relatively isolated from other grids in the U.S.. The ERCOT grid is also its own interconnection, meaning that it is not synchronously connected to other grids in the U.S. ${ }^{13}$. It does have several small, asynchronous connections to neighboring grids, but less than $1 \%$ of daily generation is exchanged over these connections. This means that wind generation in Texas directly displaces other generators on the same grid. This allows me to restrict my analysis to Texas and not model the national grid.

Third, Texas was the largest producer of wind power in the U.S. during this time period. In mid $2007,27 \%$ of all wind power capacity in the U.S. was located in Texas, with 3,352 installed MW of capacity (AWEA 2008). Almost all of Texas' capacity was built after the federal production tax credit was instituted. California had the second largest installed capacity of wind power in 2007 , with $2,376 \mathrm{MW}$, but most of the capacity was installed

13 The fact of ERCOT is also its own interconnection is quite unique. The Texas Interconnection is one of only three interconnection in the U.S.. The other interconnections, (the East and West Interconnections) are much larger than the Texas Interconnection and are comprised of many different grids each managed by separate system operators. 
before the federal PTC was instituted ${ }^{14}$. Thus, wind power in Texas represents $32 \%$ percent of new wind power facilities built from 1999-2007 under the PTC ${ }^{15}$ (EIA 2010). Measuring offset emissions on the Texas grid represents a significant proportion of total offsets the program may have achieved.

The data were provided by the Electric Reliability Council of Texas (ERCOT), which oversees the Texas grid. In the data, I observe the electrical output from each generating unit every 15 minutes, over the two year sample. For conventional generators, a generating unit is a single turbine; a power plant typically hosts several turbines. For wind farms, I observe the output of an entire wind farm which is the collection of many small turbines. Thus, for a unit that is connected to the grid for the entire sample period, I observe 70,080 output decisions. I also observe the flows of electricity over connection lines to neighboring grids, again in 15-minute intervals.

In addition to output, I know certain characteristics of each unit including fuel type, location, year online, capacity, and owner. In total, there are approximately 550 units, at 220 plants, which supply electricity to the grid managed by ERCOT.

In 2007, there were approximately 80 different firms operating the power plants which supply electricity to the Texas grid ${ }^{16}$. Combined, these generators were capable of producing over 75,000 MW of electricity, at any one time. Generation technology includes coal, nuclear, and natural gas with small amounts of hydro, landfill gas, and various fossil fuel burning generators. Table 1 shows the capacity by year, fuel type, and technology.

Emissions data comes from the Environmental Protection Agency's (EPA) eGRID

14 Texas and California together accounted for $45 \%$ of installed wind capacity in the US in 2007.

15 The next highest contributor to net wind capacity levels over this period was Iowa which contributed $8 \%$.

16 There are additional firms which provide electricity on private networks, but which do not provide electricity to the grid controlled by ERCOT. 
program. The data was collected at the plant level from a variety of sources, including Energy Information Administration (EIA) surveys and the EPA's own Continuous Emission Monitoring data. The EPA provides annual average emissions rates for $\mathrm{CO}_{2}, \mathrm{SO}_{2}$, and $\mathrm{NO}_{\mathrm{x}}$ for each plant in terms of mass per MWh of electricity produced. Although the EPA data only provides emissions rates at the plant level, this will only be a problem if units at the same facility have very different emissions rates. Since the turbines at a power plant are typically constructed with the same technology, it is reasonable approximation to assume that each unit at the plant produces emissions at the average plant rate.

I also obtained hourly temperature data from the National Weather Service for the time of the data sample. I constructed average temperature data for each hour from weather stations in or near major centers of electricity demand.

While the analysis will be conducted at the turbine level for most units, I aggregate the output of combined cycle gas generators to the plant level. Combined cycle gas technology is unique in that it utilizes multi-stage turbines to achieve higher efficiencies. The plants utilize waste heat from first-stage combustion turbines to drive second-stage steam turbines. Due to the complementarities between turbines at the same plant, the relevant output decision is made on the plant level rather than on the generator level. Thus, for combined cycle power plants in my sample, I aggregate the output of the individual turbines to the plant level. After aggregation, the 543 turbines I observe in the data collapse to 387 generating units.

For the analysis, I drop generators that appear infrequently in the data. First, I exclude 39 generators that appear in the sample, but never actually generate electricity. Second, I drop 15 generators that produce for fewer than five hours over the 2 year sample period. These 
generators don't play an economically significant role, relative to wind power. Finally, I exclude from the analysis one additional generator that appears in the data for fewer than 30 days. Since this generator exits soon after the beginning of my sample it is econometrically difficult to estimate the necessary model parameters with less than 30 days of data. In total, 55 generators are excluded from the sample. The remaining 332 generators are left as potential substitutes for wind power. Collectively, they account for more than $99 \%$ of both capacity and production in ERCOT.

\section{Electricity Market}

\section{ERCOT Introduction}

Before detailing the model, I first explain the basic structure of power systems and the institutional details of ERCOT which will motivate my estimating equation. The ERCOT grid operates as a quasi-deregulated electricity market which serves most of the state of Texas. It operates almost independently of other power grids with very few connections to outside markets. Electricity generation and retailing are deregulated while the transmission and distribution of energy remains regulated to ensure that competitors in the generation and retailing markets have open access to buy and sell power. Unlike many regulated and even deregulated markets, companies in this market are vertically separated. There are no vertically integrated firms that control generating, transmitting, and retailing resources.

\section{Power System Basics}

An electric system is physically composed of three main parts: facilities which generator electricity, a transmission system to transport the power, and end-users which draw power 
from the transmission grid. Markets for electricity are a bit unusual in that the production, transmission and consumption of electricity occur at almost the same instant. It is important for the injection of electricity into the grid by generators, and the withdrawal of power by consumers, to be nearly perfectly balanced at every point in time ${ }^{17}$. An imbalance in the production and consumption of electricity leads to changes in voltage on the power grid, with adverse consequences. For example, consuming more energy than is generated leads to dropping electrical voltage, which results in brownouts and in some cases leads to blackouts. Excess production, on the other hand, leads to voltage spikes, which can damage electrical equipment. Balancing the supply and demand for electricity is one of the key challenges electricity markets face on a daily basis. Accommodating the exogenous production of wind power requires other generators to adjust their production accordingly.

\section{Consumer Demand}

The sale of electricity to end-users is deregulated in Texas. Multiple retailers compete to sell electricity to the same consumers at a given location. For example, a resident in Houston may have three different electricity providers to choose from, each offering several electricity purchase plans. The plans vary in their price level, price variability, contract length and brand name.

As in most electricity markets, consumers in ERCOT do not respond directly to wholesale price signals. Residential and commercial users purchase electricity at fixed prices which are constant for a period of time, ranging from one month to several years. As such, users have no incentive to reduce consumption when wholesale prices increase during peak

17 Small amounts of electricity storage capacity exist on some grids, but there are no electricity storage facilities on the ERCOT grid. 
daily, or even seasonal, demand periods ${ }^{18}$

For periods where consumers face a constant price for electricity, swings in demand for electricity are driven by exogenous forces, such as temperature variation and diurnal patterns of human activity, which are not influenced by prices in the wholesale markets. For example, energy usage will be higher on a hotter day than a cooler one. Likewise, energy consumption will be higher during the day than during the night, even for the same temperature range.

This means that, conditional on a constant pricing mechanism, demand can be treated as function of exogenous variables.

$$
\text { Demand }_{t}=D\left(Z_{t} \mid \text { price }\right)
$$

For example, if consumers have contracts for electricity which allows prices they face to vary on a monthly basis, electricity demand variations within a given month will be exogenous. Over a longer period of time, as prices in the wholesale markets change, prices facing consumers will also change and demand will respond accordingly. Over the period of my analysis, I do observed pricing plans in which rates could change on a monthly basis. I do not observe pricing plans that varied on the daily or hourly level, implying that, at least within a month, demand variations for electricity will be exogenous.

18 Some large industrial consumers do curtail electricity use when reserve capacity becomes short but they do not directly respond to fluctuations in the price of electricity in the wholesale market. These large industrial users negotiate lower energy prices by agreeing to have their supply of electricity temporarily interrupted in emergency situations, when generating reserves on the grid reach critical levels. Industrial users with interruptible loads are called Loads Acting As Resources (LaaRs). In the event of an unexpected change in load, electricity delivery to the LaaR will be interrupted to maintain the frequency on the grid. Approximately half of responsive reserve services are supplied by LaaRs . Again, it is important to note that LaaRs respond to events that threaten the reliability of the grid, not to price changes in the wholesale market. Conversations with ERCOT indicated that such circumstances occur infrequently, perhaps several times a year. It is possible that industrial users could respond to price changes in the wholesale market through conditions in bilateral contracts with generators. However, I have not found any evidence to substantiate this. 


\section{Firm Production}

The structure institutions of the wholesale market reveal the incentives underlying production for conventional generators and will motivate the model in the next section. On the ERCOT grid, incentives to generate electricity are driven by wholesale prices for electricity. Firms producing electricity generate revenue in one of two ways. Either they sell power through bilateral contracts or they sell their power and capacity in markets administered by ERCOT. The larger of these two, in terms of electricity sales, is the bilateral market where almost $95 \%$ of power generated for the grid is transacted. The primary purpose of the markets administered by ERCOT is to ensure the reliability of the grid. The largest of the ERCOT administered markets is the Balancing Market, a real-time auction that which helps to balance supply and demand. The Balancing Market accounts for almost $5 \%$ of electricity sales.

To ensure that there is sufficient supply of electricity to satisfy demand, ERCOT requires generators to submit information about their willingness and intention to supply electricity in the form of scheduled energy production and associated bidding functions. The energy schedules state the firm's intended hourly output from their portfolio of generators for each hour of the day. Bidding functions are also submitted for each hour of the day which gives the portfolio's willingness to deviate from its scheduled production as a function of the wholesale market price.

ERCOT allows firms to submit day-ahead schedules which leave them in long or short positions entering into the production period. For example, a retailer of electricity could schedule electricity deliveries for half of its expected contracted demand with the intention to satisfy the rest of its contracts by purchasing power in the Balancing Market. This 
allows for considerable flexibility for firms to arbitrage between bilateral markets and the spot market regardless of their contract positions.

After schedules and bids are submitted, they can be updated by the firm up to 90 minutes prior to actual production time. This allows firms to incorporate any new information about the state of the market into their operating plans and bids approximately two hours before production is executed.

ERCOT uses the Balancing Market to match actual generation and actual demand throughout the day. The Balancing Market is cleared every 15 minutes throughout the day and 30 minutes before actual production begins by aggregating the hourly bidding functions submitted by firms and intersecting the supply curve with expected demand. The winning entities are then notified of the increase or decrease in production they will need to make relative to their scheduled production ${ }^{19}$. The Balancing Market not only smooths out deviations between supply and demand, but it also facilitates the least cost provision of electricity by substituting production from firms with low bids for production for firms with high bids, even in the case where aggregate supply does not change ${ }^{20}$.

The Balancing Market is also used to manage transmission congestion. The grid is organized into four zones, North, South, West, and Houston, based on transmission bottlenecks. If there is no congestion between zones, then the market clearing prices in the Balancing Market are the same in each zone and the entire grid acts a single market. If

19 Since Balancing Market is only cleared every 15 minutes and 30 minutes ahead of real-time production, it cannot supply the nearly continuous need to balance supply and demand. Second-by-second balancing of supply and demand comes from generators which provide regulation services. These generators provide ERCOT with direct control to part of their generator's output. ERCOT uses these generators to instantaneously follow fluctuations in grid frequency. ERCOT uses the Balancing Market to ensure sufficient reserves of regulation.

20 For a more detailed exposition of the mechanisms of the Balancing Market, I refer the interested reader to Hortacsu and Puller (2008). 
transmission lines between zones reach their capacity limit, then ERCOT intersects the bidding functions separately by zone to achieve market clearing prices for each zone which do not exceed the transmission capability between zones. For example if more power is needed in the South zone, but the transmission lines transmitting power into that zone are at capacity, ERCOT will raise the prices in the the South zone, while lowering or keeping constant the prices in the other zones ${ }^{21}$.This will increase power production in the South zone while reducing production in other zones to decrease the amount of power flowing over transmission lines into the South zone. In uncongested periods, ERCOT does not differentiate between remote generators, such as wind power, that make extensive use of transmission lines and those which are located in close proximity to load centers and thus place lower demands on the transmission network.

21 Congestion can also arise within zones. This type of congestion cannot be resolved with market prices since there is only one price for each zone. To deal with local congestion, ERCOT deploys generators out of bid order. That is, ERCOT deploys specific generators which are not willing to increase production at current prices by offering them prices higher than the prevailing market price. The costs of deploying these resources to alleviate local congestion is covered by an output tax levied on all generators in the zone. 


\section{Model}

The estimation strategy used in this paper relies on the exogeneity and randomness inherent in wind patterns which drive wind power production to identify the generating substitutes for wind power on an electricity grid. However, as previously highlighted, the diurnal and seasonal patterns of wind are not uncorrelated with other incentives for production for conventional generators. In this model, I will need to control for factors that affect a conventional producer's decision to generate electricity, which may also be correlated with wind power production. In the following, I delineate the dynamic optimization problem facing conventional generators on the grid, not to derive its solution, but to motivate the selection of controls in reduced-form estimating equation.

As shown in previous sections, the ERCOT electricity market is a composition of several markets which provide energy to the grid. In particular, generators decide between selling power in the bilateral market or bidding it into the Balancing Market ${ }^{22}$. For expositional purposes, suppose that each firm owns a single generator, though it need not be so.

Every day, each forward-looking firm submits to ERCOT its scheduled output,, and a bidding function, $q_{i t}^{b}\left(P_{t}^{b}\right)$, which gives the willingness of the firm to increase or decrease production as a function of the market clearing price in the Balancing Market in each period. In addition, the firm must decide how much energy it will commit to provide through bilateral contracts, $q_{i t}^{c}$, at the price, which is set at the time the contract is written. These bilateral contracts may be "sunk," in the sense that they have been decided on much earlier, or they may be day-ahead bilateral contracts for electricity which firms

22 Here I am abstracting away from other markets available to generators, such as selling capacity into regulation, reserve, or other ancillary service markets, which provide reliability. While important to ensuring grid reliability, these markets provide a very small proportion of energy on the grid. 
sell when making their daily energy schedules ${ }^{23}$.

Dynamics enter the model through the costs of production. Firms cannot instantaneously, or costlessly change the output of a generator, as a static model would imply. Rather, there are significant costs associated with starting up and shutting down generators, as well as ramping costs associated with changing the level of production ${ }^{24}$. The cost function, then, depends not only the current level of production, but the past level of production as well. Firms need to be forward-looking, since the current period's actions have implications for future profits. The cost function is notated as $C\left(q_{i t}, q_{i t-1}\right)$ where $q_{i t}=q_{i t}^{s}+q_{i t}^{b}$ is the actual generation of the firm in period t. The period profit function can be written:

$$
P i=P_{t}^{b}\left(q_{i t}^{b}\left(P_{t}^{b}\right)\right)\left[q_{i t}^{b}\left(P_{t}^{b}\right)+\left(q_{i t}^{c}-q_{i t}^{s}\right)\right]+P_{t}^{c} q_{i t}^{c}-C\left(q_{i t}, q_{i t-1}\right)
$$

In this equation, is the expected residual inverse demand function in the Balancing Market facing the firm, $P_{t}^{c} q_{i t}^{c}$ is its financial position in the bilateral market, and $\left(q_{i t}^{c}-q_{i t}^{s}\right)$ is the net long or short position of the firm going into the production period.

The timing of the decision process is as follows. The day before production the firm finalizes its bilateral contracts for the delivery of power. It then submits to the grid manager, its scheduled production and a bid function for the Balancing Market, showing its willingness to deviate from that schedule. As production time draws nearer, the firm may update its schedule and bid functions as it receives additional information about the likely state of the market. This may continue until 90 minutes prior to production, at which point

23 Contract length can vary, from contracts several years in length to simple day-ahead contracts. There is active trading for day-ahead contracts in the bilateral market. In addition, contract prices are often tied to fuel prices, or even to market clearing prices, in the balancing market. Conversations with energy traders indicate that approximately a quarter of contracts they see are of the latter type. These types of contracts are called financial swaps, and guarantee delivery of electricity, which is settled ex-post at the market clearing price.

24 See Cullen (2010) and Mansur (2008) for a more detailed discussion of generator level dynamics. 
its schedule and bid function are fixed. Thus, the payoff for the firm in the current period is determined by its actions, which were set a least $\tau$ periods ago (where

$$
\tau=90 \mathrm{~min} / \text { period length }) \text {, and by contemporaneous shocks to the system. I can write }
$$

the dynamic programming problem solved by the firm as the following Bellman equation:

$$
V\left(\Omega_{t}, q_{i t}^{s}(.), q_{i t}^{c}\right)=\max _{q_{i t+\tau}^{s}(.), q_{i t+\tau}^{c}} \Pi_{t}\left(\Omega_{t}, q_{i t}^{s}(.), q_{i t}^{c}\right)+\beta E V\left(\Omega_{t+1}, q_{i t+1}^{s}(.), q_{i t+1}^{c} \mid \Omega_{t}, q_{i t}^{s}(.), q_{i t}^{c}\right)
$$

where $q_{i t}^{s}($.$) is the bidding function and q_{i t}^{c}$ is production which are submitted by the firm in period $t-\tau$ and $\Omega_{t}$ is the information set of the firm at time period t. The information set is used by the firm to set its actions. which will be executed periods in the future ${ }^{25}$. The firm's solution to this dynamic programming problem is an optimal policy function which gives the optimal quantity to schedule for production and the optimal bid function in the spot market given the current information in the market. The observed quantity produced by firm $\$ \mathrm{i} \$$ is then determined by the following factors: (1) its equilibrium optimal policy function, (2) the policy functions of its competitors, and (3) the current realization of market demand and wind power production.

This paper does not attempt to explicitly solve the dynamic optimization problem facing the firm, as does Cullen (2010). However, the dynamic model illustrates that the estimating equation will need to not only control for contemporaneous variables, but also for elements of the informations set $\Omega_{t-\tau}$, which the firm considers when adjusting its optimal

25 The dynamic problem for a firm with multiple generators is similar only with a more complex cost function which depends not only on the total output of the firm, but also on the amount each generator produces. Thus the choices of the firm include not only the firm level contract quantity and bidding function, but also which generators will produce the output. 
bidding function and energy schedule. In particular, this implies that information prior to the current period will be an important determinant of current output, both because of the timing of the decision and to account for firms' expectations in the dynamic framework. Also, note that wind-generated electricity does not change a firm's output decision directly. Rather, wind-generated electricity, as a zero marginal cost producer, shifts the residual demand function facing the firm.

\section{Estimation}

The estimation approach used in this paper exploits the randomness and exogeneity of wind patterns to identify the average reduction in output for each generator on the grid due to wind power production. As was noted in the previous section, the dynamic nature of the output decision informs the controls that will be used.

The final estimation equation will be akin to estimating the optimal policy function coming from the dynamic programming problem for each of the generators, in reduced form. The actual optimal policy function will not be estimated, since the true policy function for a firm maps the information set of the generator into a optimal schedule and bidding functions rather than into output. Instead, this paper will estimate a reduced form function that maps the firm's information set onto the realized output of the generator, given its optimal policy. A generator's realized output results from the combination the following factors: (1) its own optimal policies, which it sets at least 90 minutes prior to actual production, (2) the policies of other firms, and (3) the realized levels of demand and wind power in the actual production period.

The estimation procedure will be performed separately for each generator on the grid to 
allow for complete flexibility across generator characteristics. The wide variety in generator technologies and vintages imply generators face vastly different cost structures and production incentives. Marginal costs and dynamic constraints, such as startup costs and ramping rates, can vary by orders of magnitude across generators. In addition, two technologically identical generators may respond differently to wind power production because of their geographic location on the grid or because of their ownership structure, which will influence their incentives to respond to price changes induced by exogenous wind power production.

This significant heterogeneity across generators demands that the greatest possible flexibility be built into the estimation strategy. Accordingly, for each generator, , I separately estimate a production equation and I do not place any cross equation restrictions on the estimation method. Realized output is modeled as a function of wind power and associated controls, as shown below:

$$
q_{i t}=f\left(\text { Wind }_{t}, Z_{t}, \Omega_{t-\tau}, \epsilon_{i t} \mid \theta\right)
$$

where $q_{i t}$ is the observed quantity of electricity produced by generator $i$ in each 15 min time period $t, Z_{t}$ is a set of contemporaneous controls, and $\Omega_{t-\tau}$ is information about the state of the market which the generator used when setting its currently executed actions which were decided $\tau$ periods previously. Note that $\Omega_{t-\tau}$ is indexed only by $t$ and not by $i$. That is, I am assuming that firms have a common information set in each period. Firms in this market have access to an extraordinary amount of information 
about the state of the grid in terms of load, congestion, weather, rivals' costs and production decisions, and wind power production in real-time. Some of this information, such as system demand, is provided directly by the grid manager. Other information, such as the operating decisions of other generators on the grid, is provided by private companies which monitor the grid. The wealth of information available in this market makes a common information assumption plausible.

The notable exception to the common information assumption is information about rivals' forward contract position. Contract positions have the potential influence to operations decisions only when a firm can exercise market power. Since this information is proprietary, I do not observe it for any of the generators. I cannot control for it directly, but will attempt to control for it indirectly.

The functional form used to estimate the function above is a simple linear model with quadratic expansions of the variables to allow for non-linearities inherent in the underlying model. Current aggregate wind power production, the element of interest, is included in quadratic form. Contemporaneous controls that would effect output include aggregate demand, temperature, and a dummy, indicating if key transmission lines are congested. Remember that since consumers face constant retail prices, demand in this market is not responsive to wholesale electricity prices, but driven by exogenous variables such as weather, day of week, and time of day. Temperature is included separately, due to its direct effect on generator efficiency; higher outside temperatures reduce the efficiency of the thermodynamic cycle used to drive turbines and lower a generators effective capacity. For the empirical specification, I assume $\tau$ periods cover 2 hours of time. This is slightly longer than the 90 minute deadline enforced by ERCOT which accounts for the fact the 
firms must gather and process the information before submitting updated bids and schedules.

The elements of $\Omega_{t-\tau}$ need to include the information firms use when making their decisions 2 hours prior to production. The empirical implementation of the firm's information set includes lagged demand, wind power, temperature, and congestion information. I include the hourly average of these variables for each hour, starting 25-hours prior to the production period, up to the period 2-hours prior to production. Thus there are 92 lagged variables each with a quadratic expansion. One reason to include such an extensive set of lagged controls is to control for firms' expectations. For this time period, I do not know firms' expectations for demand or wind output. Rather, I assume that they use the evolution of demand, wind, and temperature in their information set, gathered over the 25-hours previous, to create their forecasts.

To capture dynamic constraints, I include the operating state for the generator, two hours prior to production. A generator which is not operating will incur startup costs if it called upon to produce electricity during the production period. Because of this, a generator idle two hours before production starts, is less likely to operate during the production period. To capture potential strategic interactions, I also include the operating state of all the other generators on the grid for the same time period. The operating state, whether the unit is on or off, of each rival generator can provide information about the potential profitability for operating in the production period.

In addition, I include dummies to control for daily variables which would affect deployment and operation decisions. Some of these variables are potentially observable such as daily spot prices for natural gas, generator's outage status, or the outage status of 
competing generators. Others are not observable, such as firms' forward contract positions or changes in the price of consumers contracts for retail power. Including, day by year dummies (i.e. date dummies) controls for both observable and unobservable factors that vary by day. The remaining within-day variation of wind power will be used to identify generating substitutes.

There is some concern that the date dummies may sweep out important identifying variation in wind power across days which might impact the estimates. As an alternative to including date dummies, I include in the appendix an alternate specification that controls explicitly for the observable factors of fuel prices and generator outages and also includes month by year dummies to control in part for unobservables. The general results coming from the alternative model are nearly indistinguishable from the current model. A complete discussion of the alternative specification and results can be found in appendix A. To summarize, the estimation equation will include contemporaneous wind power production in quadratic expansion, 4 contemporaneous controls ( 7 including quadratic expansion terms), 92 lagged controls (161 including quadratic expansion terms), 332 dummies for the lagged operating state of generators, and 730 date dummies. This set of variables (see table 2), while not entirely exhaustive, provides a rich set of controls for incentives that a generator may face which may also be correlated with wind power production.

The estimation proceeds for each of the 332 generators, using OLS with the flexible polynomial expansion of the variables: 


$$
q_{i t}=\beta_{i 0}+\beta_{i 1} \text { Wind }_{t}+\beta_{i 2} \text { Wind }_{t}^{2}+Z_{t} \gamma_{i}+D_{t} \alpha_{i}+\epsilon_{i t}
$$

where Wind $_{t}$ is the amount of wind power produced in the current 15-minute time

period, $Z_{t}$ are the contemporaneous and lagged control variables in quadratic expansion, and $D_{t}$ are date dummies.

Since the information set is common across the estimating equations there is no efficiency advantage to using seemingly unrelated regression techniques. Also, although we would expect the sum of the marginal impacts to sum to approximately one, I do not impose constraints which would require $1 \mathrm{MWh}$ of wind power to offset $1 \mathrm{MWh}$ of conventional generation. Since wind power is not produced near demand centers it could be that the offsets could be less than one-to-one due to transmission line losses, if wind power is a substitute for generators which are closer to demand centers.

\section{Results}

Results were obtained by estimating each equation as specified in the previous section. The parameters of interest in each equation relate to the impact of contemporaneous wind output on the conventional generators' output over the sample period. Using the estimated coefficients from each regression, marginal substitution parameters for wind power can be calculated for each generator. The substitution parameter is defined as the derivative of the estimating equation with respect to contemporaneous wind power production, as is shown in the equation below. 


$$
\frac{\partial f\left(\text { Wind }_{t}, Z_{t}, \Omega_{t-\tau}, \epsilon_{i t} \mid \theta\right)}{\partial \text { Wind }_{t}}=\beta_{i 1}+2 \text { Wind }_{t} \beta_{i 2}
$$

To evaluate the derivative, I use the average wind power production over the generator's

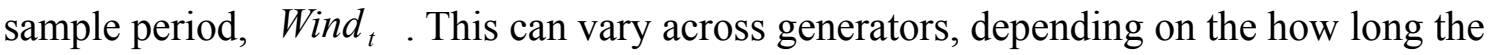
generator is in the sample, However, since $95 \%$ of the generators are present for the entire period of the sample, this value will be identical for most generators ${ }^{26}$.

Due to the large number of generators, only a subset of generator-level substitution parameters are reported in this paper $^{27}$. Table 3 shows the substitution parameter estimates for the top ten substituting generators. The second column shows the estimated substitution parameter for the generator, followed by the standard error of the estimate in column three. A substitution parameter of -0.1 would imply that a single generator reduces its output, on average, by one tenth of a MWh for each MWh of wind power that is produced. The estimates show that the offsets from wind power are not concentrated in any single generator. In fact, the most substitutable generator reduces its output on average by 0.05 MWhs for an additional unit of wind power. Given the networked nature of the grid, the complex way in which electricity flows, and the large quantity of wind power, it is not surprising that offsets are not heavily concentrated in a single generator. However, together the top ten generators do account for $34 \%$ of power offsets.

Table 3 also provides information on the generators fuel and technology characteristics. Of the top ten generators, 5 are coal-fired power plants, 3 are combined cycle gas generators and 2 are gas steam turbines. The fact that five of the top ten substituting plants are coal

26 Only 16 of 332 generators are not present for the entire sample.

27 Complete estimation results are available on the author's website. 
plants contradicts what a static model would predict. Coal plants reducing output when wind power is produced is consistent with the propensity of wind power to produce most vigorously at night when coal plants are closer to being marginal. Given that coal plants are the "dirtiest" polluters, this means that wind power may be offsetting more emissions than one might otherwise anticipate.

The last three columns in the table show the generator's maximum output capacity, its contribution to total grid wide capacity, and its market share of electricity production. The top ten generators tend to be larger generators, but are being offset in high rations relative to their market shares. The top 10 substitution generators account for $34 \%$ of offset power, but only $10 \%$ of capacity, and $13 \%$ of actual production in ERCOT.

The offset emissions for each generator can be found in table 4. Emissions considered in this paper include $\mathrm{SO}_{2}, \mathrm{NO}_{x}$, and $\mathrm{CO}_{2}$. Given the estimated generator level substitution parameters, emission offsets are calculated by multiplying the EPA's average emissions rate for the plant by the estimated substitution parameter. For each emissions type and generator, the quantity of emissions offset per MWh of wind power is listed in the table. Also included are the generator's offsets as a percent of total estimated offset emissions. The four coal units account for nearly all of the of $\mathrm{SO}_{2}$ offset from the top ten generators, due to fact that gas plants have negligible $\mathrm{SO}_{2}$ emission rates. These five coal plants also account for $73 \%$ of grid-wide emission offsets of $\mathrm{SO}_{2}$. They also have higher emission offsets for $\mathrm{NO}_{\mathrm{x}}$ and $\mathrm{CO}_{2}$ which are on the order of 2-4 times greater than the gas plants in the table. Together the top ten generators account for roughly one-third of all $\mathrm{NO}_{\mathrm{x}}$ and $\mathrm{CO}_{2}$ wind-generated emission offsets.

Table 5 shows similar results for increasingly comprehensive subsets of the generators. The 
pattern of substitution is fairly concentrated with the top 50 generators accounting for most of the power offsets. Note that the sum of offsets for all generators is slightly greater than one, since the model does not place a restriction on the system of the equations to require that one MWh of wind power offset one MWh of conventional production. However, we cannot say that the sum of the power offset is statistically different from one ${ }^{28}$. Figure 3 illustrates the distribution of the estimated substitution parameters graphically, by plotting the cumulative substitution effect starting with the generators with the largest offsets and ending with the lowest offsetting generators. All generators are included in this graph, regardless of whether or not their individual coefficients are statistically significant or not. Note that there are a number of generators that have positive estimated substitution parameters, though many of these are statistically insignificant.

Table 6 shows the emission offsets for the same groups. In aggregate, each MWh of wind power offsets approximately $3 \mathrm{lbs}$ of $\mathrm{SO}_{2}, 1 \mathrm{lb}$ of $\mathrm{NO}_{\mathrm{x}}$, and more than three-quarters of a ton of $\mathrm{CO}_{2}$. This grid-wide emissions offset profile will be used in the next section when calculating the value of emissions offset by wind power.

Breaking down the gross substitution by fuel type and technology gives another view of the patterns of offsets. Table 7 shows estimated power offsets by fuel type. The vast majority of production that is offset comes from gas-fired power plants, which reduce output by $0.72 \mathrm{MWh}$ for every MWh of wind produced. These production offsets represent a non-trivial reduction 3\% of total production of gas power plants. However, offsets by coal plants are not insignificant, reducing output by $0.28 \mathrm{MWhs}$ for each unit of wind power. Their contribution to emission offsets, as shown in Table 8, is even more

28 Throughout the paper, the standard errors for the sum of parameters across generators was calculated under an independence assumption. That is, the variance of the sum of the parameters is the sum of the variances on each parameter. Any covariance terms were not taken into account. 
significant due to their higher emissions rates; they account for nearly half of $\mathrm{NO}_{\mathrm{x}}$ and $\mathrm{CO}_{2}$ offsets and almost all of $\mathrm{SO}_{2}$ offsets.

Altogether the estimates imply that over the sample period, 18,000 tons of $\mathrm{SO}_{2}, 6,000$ tons of $\mathrm{NO}_{\mathrm{x}}$, and over 9 million tons $\mathrm{CO}_{2}$ were offset by wind power production. Table 9 shows these offsets and notes these represent roughly two percent of emissions from conventional power production over the sample period. In the following section, I propose a way to value these emissions and relate them to the subsidies necessary to induce wind power production.

\section{Valuing Offset Emissions}

Given the estimates of emissions offset by wind, we can now attach a monetary value to these offsets. This allows us to compare the value of emissions with the costs of subsidizing wind-generated power production ${ }^{29}$. Given the estimated emissions offset, the value per MWh of wind power can be calculated using any defined value.

When choosing values for offset emissions, it is important to note that offset emissions do not necessarily imply a reduction in total emissions of that type. For emissions regulated under a cap-and-trade framework, emissions offset at one facility result in pollution permits being freed up for use elsewhere. For example, if a coal plant reduces its output, and therefore $\mathrm{SO}_{2}$ emissions, due to wind energy production, it now has pollution permits available to use or sell on the open market. As long as the pollution caps are binding, pollution offset by wind power will be emitted elsewhere. Firms will reduce costly abatement as a result of clean energy production and total pollution will not decrease. Both

29 While I propose one set of values for emissions, many others could be used to calculate the monetary value offsets. Given the estimated offset quantities, such calculations are very simple to complete. 
$\mathrm{SO}_{2}$ and $\mathrm{NO}_{\mathrm{x}}$ are regulated under cap-and-trade type policies. For unregulated emissions, such as $\mathrm{CO}_{2}$, emissions offset by wind power result in a real reduction of total emissions of that type $\mathrm{e}^{30}$.

Choosing an appropriate value for offset emissions depends, in part, on how the pollutant is regulated. For unregulated pollutants where offsets result in real reduction of overall level of emissions, the appropriate value for offset emissions is ostensibly the social cost of the pollutant. The only unregulated pollutant I measure is $\mathrm{CO}_{2}$. Given the current concerns regarding global climate change, there have been many studies which estimate the social value of reducing $\mathrm{CO}_{2}$ emissions. I will appeal these estimates when calculating the value of $\mathrm{CO}_{2}$ emissions offset by wind power.

For pollutants under cap-and-trade regulation, selecting the appropriate measure for the value of offset emissions is more nuanced. Since the overall quantities of pollutants remain constant, there may not be any social benefit of emission offset under cap-and-trade regulation ${ }^{31}$. Thus, using the social cost of such pollutants would not be appropriate. Another natural candidate would be the market clearing price for pollution permits . Such data is widely available and represents market value for pollution reduction, given the cap. However, because the costs of emissions are already internalized by firms and consumers through the permit prices, there are no social benefits of offset emissions.

However, one may be able to envision a policy scenario in which the permit price may be the appropriate value of emissions. Suppose that government wants to lower the number

30 If pollutants were regulated under emissions rate regulation, as has occurred in the past, offset emissions might also represent real reductions in pollution. However, none of the pollutants under consideration are regulated in this manner.

31 Although the aggregate emissions of a cap-and-trade regulated pollutant will not change, the timing or location of the emissions may change. The shifting of the distribution of pollutants may be welfareenhancing, but is beyond the scope of the paper. 
of available permits in the market. It may well be politically infeasible to simply lower the cap and "take away" pollution permits from firms. However, the government could simply buy and retire permits on the open market thereby effectively reducing the pollution cap, with no impact on the firms' bottom line. An alternative policy to achieve the same objective could be to subsidize wind power while simultaneously reducing the cap by the quantity of pollution offset by wind power. Such a policy might be politically feasible since firms do not incur additional abatement costs and the industry receives subsidies. Therefore, under the assumption that both policies are politically feasible, we could compare the cost of wind subsidies with the cost of buying and retiring pollution permits to achieve a similar reduction in pollution. Both policies reduce pollutants by the same amount, but may do so at different costs. Thus, for the evaluation of cap-and-trade emissions, I use market clearing prices for pollution permits.

For the purposes of this paper, I will use different measures to value pollution for regulated and unregulated pollutants. For the regulated pollutants $\left(\mathrm{SO}_{2}\right.$ and $\left.\mathrm{NO}_{\mathrm{x}}\right)$ I use permit prices while for $\mathrm{CO}_{2} \mathrm{I}$ use estimates of the social cost of carbon. The range of permit prices come from historical transactions of $\mathrm{NO}_{\mathrm{x}}$ and $\mathrm{SO}_{2}$ pollution permits, while values for the social cost of carbon come from prior studies.

Given the importance of $\mathrm{CO}_{2}$ for climate change, a large body of literature exists on the estimated damages of $\mathrm{CO}_{2}$ emissions. Tol (2005) reviews the literature, which estimates the social costs of $\mathrm{CO}_{2}$, and concludes that the costs imposed by $\mathrm{CO}_{2}$ are less than $\$ 50 /$ ton and probably significantly lower than that. The median marginal damage costs of $\mathrm{CO}_{2}$, as found in papers published in peer-reviewed journals, was $\$ 14$ /ton (Tol 2005).

In addition, the U.S. Government has recently compiled estimates on the social cost of 
carbon for use in regulatory analyses. The Interagency Working Group On Social Cost Of Carbon compiled the report which estimates the monetized damages associated with an incremental increase in carbon emissions in a given year. The group selected four values which are based on a collection of integrated assessment models, at discount rates of 2.5, 3, and 5 percent. The values for the social cost of carbon produced by the report were $\$ 5$, $\$ 21$, and $\$ 35$, per ton of $\mathrm{CO}_{2}$ for the year of 2010 , with $\$ 21$ being the "central” value. The fourth value, of $\$ 65 /$ ton $\mathrm{CO}_{2}$, was included to "represent higher-than-expected impacts" from climate change (United States 2010).

Table 10 shows the values used for pollution permits or social costs for valuing offsets. I chose $\$ 5, \$ 21$, and $\$ 35$ per ton as a range of possible social values for reducing $\mathrm{CO}_{2}$ emissions as outlined. The middle-range values for $\mathrm{NO}_{\mathrm{x}}$ and $\mathrm{SO}_{2}$ represent the mean value of pollution permits in the transaction data, while the high and low values roughly correspond to values from the $95^{\text {th }}$ and $5^{\text {th }}$ percentiles of the price distribution in my transaction data.

Using these values for pollutants, we can now put a price on the value of emissions offset by wind power. Table 11 shows the value of offset emissions for the low, mid and high ranges of pollutant values. Thus, valuing pollutant reduction in this way yields estimates for the benefits of wind power ranging from $\$ 5-\$ 34$ per MWh produced. It is immediately apparent that the value of emissions offset by wind power depends heavily on the social cost of $\mathrm{CO}_{2}$, which accounts for roughly $80 \%$ of the value of offset emissions in each scenario.

We can now compare the market price of offset emissions to the subsidy received to induce the investment in wind power. As previously discussed, wind farms receive federal PTC 
subsidies of \$20 MWh for the first 10 years of operation. In addition to Federal subsidies, wind farms receive a renewable energy credit from the state of Texas, under the Renewable Portfolio Standard, for each MWh of power produced. The market value of these credits ranges from $\$ 5$ - $\$ 10$ / MWh. In total, Texas wind energy receives $\sim \$ 30 \mathrm{MWh}$ in subsidies. However, this overstates the cost of the subsidy per MWh of wind power because it implicitly assumes that firms end production when the PTC expires, 10 years after completion of the project. Given that the marginal cost of operating a wind farm is quite low, we would expect established wind farms to continue their operations after the expiration of the PTC for that farm. Under the assumption that wind farms continue to operate after PTC benefits expire and continue to receive a state subsidy of $\$ 10 / \mathrm{MWh}$, the discounted cost of the subsidy is $\$ 20 / \mathrm{MWh}$ over the life of the wind farm, given that the subsidies and value of emissions change with the same discount rate.

Now we can compare the $\$ 20 / \mathrm{MWh}$ subsidy received by wind farms with the value of emissions offset. Table 11 clearly shows that with the intermediate pollutant values, the estimated value of offset emissions is $\$ 19.81 / \mathrm{MWh}$, which nearly the same as the subsidies received by wind farm operators to induce investment. Under the assumption that no wind capacity would be installed without state and federal subsidies, it could be argued that the environmental benefits of wind power are equal to the cost required to spur the production of wind energy. In fact, with the social cost of carbon greater than $\$ 25.50$, the emissions benefits of wind power exceed the costs of the subsidy, based on $\mathrm{CO}_{2}$ benefits alone. This result does not imply that wind power is the lowest cost method of reducing emissions; it is almost certainly not. However, we can say that the cost subsidizing wind could be justified by the potential benefit of avoided emissions. 
It is worth reiterating at this point that this is not a comprehensive cost/benefit analysis of wind power. The implicit costs of wind power, such as the impact on grid reliability or aesthetic damage to the landscape, have not been explored. Likewise, wind power may procure other benefits, such as reduced mercury emissions or particulates, which have not been explored due to data constraints. It is also important to note that this paper does not account for every pollutant offset by wind power. However, it is clear that the benefits from reduced emissions are larger than the subsidies used to induce wind power investment for plausible valuations of pollutants.

\section{Conclusion}

Renewable energy subsidies have been a politically popular program over the past decade. These subsidies have lead to explosive growth in wind power installations across the US, especially in the Midwest and Texas. Renewable subsidies are largely motivated by their environmental benefits as they do not emit $\mathrm{CO}_{2}, \mathrm{NO}_{x}, \mathrm{SO}_{2}$, or other pollutants which are produced by fossil fuel generators. Given the lack of national climate legislation, for the foreseeable future, renewable energy subsidies are likely to continue to be one of the major policy instruments for mitigating carbon dioxide emissions. As such, a better understanding of the impact of subsidization on emissions is imperative. This paper is the

first to directly measure the impact of wind power on emissions using observed generating behavior.

The quantity of pollutants offset by wind power depends crucially on which generators reduce production when wind power comes online. By exploiting the quasi-experimental variation in wind power production, driven by weather fluctuations, it is possible to 
identify generator specific production offsets due to wind power. In this paper I have estimated the wind power offsets for generators on the Texas electricity grid. The results show that wind power crowds out, not only quick responding gas plants, but also has a significant impact of the operations decisions of baseload generators, including coal generators.

As a benchmark for the economic benefits of renewable subsidies, I compared the value of offset emissions to the cost of subsidizing wind farms for a range of possible emission values. I find that the value of subsidizing wind power is driven primarily by $\mathrm{CO}_{2}$ offsets, but that for reasonable values for the social costs of $\mathrm{CO}_{2}$, the environmental benefits of wind power have outweighed the costs of the subsidies.

These results are subject to a number of caveats. First, though subsidies could be justified by their environmental benefits, this does not imply these narrowly targeted renewable energy subsidies are the least costly way to reduce emissions. It seems likely that alternative policies which directly regulate pollutants, such as emission taxes or cap-andtrade systems, could easily achieve similar results with lower cost. Second, it should be noted that this not a complete cost/benefit analysis of wind power. Integrating wind power into the generation mix may have additional costs not considered here, such as increased supply intermittency. Third, these estimates represent the short run impact of wind power on emissions offsets. They do not account for long run incentives that wind power may create to retire or build different types of conventional generators. As such, the results can not be extrapolated to understand the long run implications of growing wind penetration. Fourth, these results are particular to the state of Texas. Their general applicability to other grids in the US or abroad will depend on the degree of similarity the grids share in terms of 
generation mix and market institutions. Texas does, however, provide an ideal laboratory for analysis due to its relative isolation and significant share of wind power.

The analysis provided in this paper provides a clear insight into the impact of wind power on fossil fuel generation and emissions for the state of Texas, with important implications for the country at large. While not a first-best policy for controlling emissions, production from wind farms, financed through renewable subsidies, does yield substantial environmental benefits which outweigh the costs of inducing investment in renewable power facilities. 


\section{References}

AWEA (2008), Factsheets, Technical report, American Wind Energy Association.

AWEA (2010), Factsheets, Technical report, American Wind Energy Association.

Baerwald, E. F., D'Amours, G. H., Klug, B. J. \& Barclay, R. M. R. (2008), 'Barotrauma is a signicant cause of bat fatalities at wind turbines', Current biology : CB 18(16). R695-R696.

Cullen, Joseph A. (2010), 'Dynamic Response to Environmental Regulation in the Electricity Industry', Working paper.

Devlin, E. (2005), 'Factors Affecting Public Acceptance of Wind Turbines in Sweden', Wind Engineering 29(6), 503-511.

EIA (2008), Technical report, Energy Information Administration. ????

EIA (2010) Electric Power Annual 2009, Technical report, Energy Information Administration.

EPA (2006), Emissions \& Generation Resource Integrated Database (eGRID), Technical report, Environmental Protection Agency.

ERCOT (2007), New electric generating plants in Texas since 1995, Technical report, Electric Reliability Council Texas.

General Electric (2005), 'The Effects of Integrating Wind Power on Transmission System

Planning, Reliability, and Operations Report on Phase 2: System Performance

Evaluation. Performance Evaluation', Prepared for the New York State Energy

Research and Development Authority.

Ladenburg, J. \& Dubgaard, A. (2007), 'Willingness to pay for reduced visual disamenities from offshore wind farms in Denmark', Energy Policy 35(8), 4059-4071.

Mansur, Eric T. (2008) 'Measuring Welfare in Restructured Electricity Markets'. Review of Economics and Statistics 90: 369-386.

Newcomer, A., Blumsack, S. A., Apt, J., Lave, L. B. \& Morgan, M. G. (2008), `Policy Analysis Short Run Effects of a Price on Electric Generators on Carbon Dioxide Emissions from U.S. Electric Generators', Environmental Science \& Technology 42(9), 3139-3144.

Potomac Economics (2007). '2006 State of the Market Report for the ERCOT Wholesale Electricity Markets', Technical Report, Electric Reliability Council Texas.

Pedersen, E. \& Waye, K. P. (2004), 'Perception and annoyance due to wind turbine noise, a dose-response relationship', The Journal of the Acoustical Society of America 116(6), 3460-3470.

Puller, S. \& Hortacsu, A. (2008), 'Understanding strategic bidding in multi- unit auctions: A case study of the texas electricity spot market', RAND Journal of Economics . 
Smallwood, K. S. \& Karas, B. (2009), `Avian and Bat Fatality Rates at Old-Generation and Repowered Wind Turbines in California', Journal of Wildlife Management 73(7), 1062-1071.

Tol, R. S. (2005), 'The marginal damage costs of carbon dioxide emissions: an assesment of the uncertainties', Energy Policy 33, 2064-2074.

United States Government (2010). Interagency Working Group On Social Cost Of Carbon, Social Cost of Carbon for Regulatory Impact Analysis Under Executive Order 12866, URL: http://www.epa.gov/oms/climate/regulations/scc-tsd.pdf.

Windustry (2008), 'Community wind toolbox: Purchase power agreements', Technical report, Windustry.

Wiser, R. \& Barbose, G. (2008), Renewables portfolio standards in the united states: A status report with data through 2007, Technical report, Lawrence Berkeley National Laboratory.

Wiser, R. \& Bolinger, M. (2006), Annual report on U.S. wind power installation, cost, and performance trends: 2006, Technical report, U.S. Department of Energy. 
Table 1:

\section{Generator Composition}

\begin{tabular}{lrrrrrrr} 
& \multicolumn{3}{c}{ Total Capacity (MW) } & & \multicolumn{3}{c}{ Share of Capacity } \\
\cline { 2 - 4 } \cline { 7 - 8 } & $\mathbf{2 0 0 5}$ & $\mathbf{2 0 0 6}$ & $\mathbf{2 0 0 7}$ & & $\mathbf{2 0 0 5}$ & $\mathbf{2 0 0 6}$ & $\mathbf{2 0 0 7}$ \\
\hline Natural Gas & 47537 & 48372 & 49109 & & $67.20 \%$ & $66.20 \%$ & $64.80 \%$ \\
Coal & 15229 & 15729 & 15762 & & $21.50 \%$ & $21.50 \%$ & $20.80 \%$ \\
Nuclear & 4887 & 4887 & 4892 & & $6.90 \%$ & $6.70 \%$ & $6.50 \%$ \\
Wind & 1545 & 2509 & 4150 & & $2.20 \%$ & $3.40 \%$ & $5.50 \%$ \\
Unknown & 856 & 856 & 1106 & & $1.20 \%$ & $1.20 \%$ & $1.50 \%$ \\
Water & 512 & 512 & 501 & & $0.70 \%$ & $0.70 \%$ & $0.70 \%$ \\
Petroleum Coke & 142 & 143 & 143 & & $0.20 \%$ & $0.20 \%$ & $0.20 \%$ \\
Diesel & 40 & 40 & 38 & & $0.10 \%$ & $0.10 \%$ & $0.00 \%$ \\
Landfill Gas & 40 & 53 & 59 & & $0.10 \%$ & $0.10 \%$ & $0.10 \%$ \\
\hline Total & 70788 & 73101 & 75760 & & $100.00 \%$ & $100.00 \%$ & $100.00 \%$
\end{tabular}


Table 2:

Estimation Variables

Independent Variables

Description

Contemporaneous Variables

Wind $_{t}$

Wind $_{t}^{2}$

Wind power production for current period $(\mathrm{MWH})$

Demand $_{t}$

Square of wind power production for current period

Demand $_{t}^{2}$

System demand for current period (MWH)

Temperature

Square of system demand for current period (MWH)

Temperature $_{t}^{2}$

Congest $_{t}$

Average system wide temperature for current period

Square of average system wide temperature for current period

Indicator for inter-zonal congestion

Lagged Variables

Operate $1_{t-9}$

$\cdots$

Operate $332_{t-9}$

Operating indicator for generator 1 lagged 2 hrs

Wind $_{t-9}$

Wind $_{t-9}^{2}$

Demand $_{t-9}$

Demand $_{t-9}^{2}$

Temperature $_{t-9}$

Temperature $_{t-9}^{2}$

Congest $_{t-9}$

$\cdots$

Wind $_{t-100}$

Wind $_{t-100}^{2}$

Demand $_{t-100}$

Demand $_{t-100}^{2}$

Temperature $_{t-100}$

Temperature $_{t-100}^{2}$

Congest $_{t-100}$

...

Operating indicator for generator 332 lagged 2 hrs

Wind power production lagged $2 \mathrm{hrs}$ (9 periods)

Square of wind power production lagged 2 hrs (9 periods)

System demand lagged 2 hrs (9 periods)

Square of system demand lagged 2 hrs (9 periods)

Average system wide temperature lagged 2 hrs (9 periods)

Square of average system wide temperature lagged $2 \mathrm{hrs}$ (9 periods)

Indicator for inter-zonal congestion lagged 2 hrs (9 periods)

$\cdots$

Wind power production lagged $25 \mathrm{hrs}$ (100 periods)

Square of wind power production lagged $25 \mathrm{hrs}$ (100 periods)

System demand lagged $25 \mathrm{hrs}$ (100 periods)

Square of system demand lagged $25 \mathrm{hrs}$ (100 periods)

Average system wide temperature lagged $25 \mathrm{hrs}$ (100 periods)

Square of average system wide temperature lagged $25 \mathrm{hrs}$ (100 periods)

Indicator for inter-zonal congestion lagged 25 hrs (100 periods)

Dummies

Day/Year Dummy for each date in the sample 
Table 3:

Top Ten Substitutes - Production

\begin{tabular}{|c|c|c|c|c|c|c|c|}
\hline \multirow[b]{2}{*}{ Unit Name } & \multirow{2}{*}{$\begin{array}{c}\text { Offset Power } \\
\text { Per } 1 \mathrm{MWH} \text { Wind }\end{array}$} & \multirow{2}{*}{$\begin{array}{l}\text { Standard } \\
\text { Error }\end{array}$} & \multirow{2}{*}{$\begin{array}{l}\text { Fuel } \\
\text { Type }\end{array}$} & \multirow[b]{2}{*}{ Technology } & \multicolumn{2}{|c|}{ Capacity } & \multirow{2}{*}{$\begin{array}{l}\text { Total Market } \\
\text { Production }\end{array}$} \\
\hline & & & & & Unit & Pct of Total & \\
\hline Big Brown Unit 2 & -0.050 & 0.0014 & Coal & Steam Turbine & 598 & $0.8 \%$ & $1.4 \%$ \\
\hline Forney & -0.034 & 0.0024 & Gas & Combine Cycle & 1770 & $2.3 \%$ & $2.6 \%$ \\
\hline Big Brown Unit 1 & -0.036 & 0.0017 & Coal & Steam Turbine & 597 & $0.8 \%$ & $1.5 \%$ \\
\hline Permian Basin Unit 6 & -0.031 & 0.0017 & Gas & Steam Turbine & 523 & $0.6 \%$ & $0.2 \%$ \\
\hline Tenaska Gateway & -0.025 & 0.0013 & Gas & Combine Cycle & 978 & $1.1 \%$ & $1.4 \%$ \\
\hline Fayette Power Unit 2 & -0.037 & 0.0011 & Coal & Steam Turbine & 608 & $0.8 \%$ & $1.3 \%$ \\
\hline Stryker Creek Unit 2 & -0.029 & 0.0034 & Gas & Steam Turbine & 499 & $0.6 \%$ & $0.2 \%$ \\
\hline Kiamichi Power & -0.042 & 0.0042 & Gas & Combine Cycle & 1151 & $1.6 \%$ & $1.8 \%$ \\
\hline Fayette Power Unit 1 & -0.032 & 0.0014 & Coal & Steam Turbine & 616 & $0.8 \%$ & $1.3 \%$ \\
\hline Monticello Unit 1 & -0.022 & 0.0010 & Coal & Steam Turbine & 551 & $0.7 \%$ & $1.5 \%$ \\
\hline lop len lotal & -0.34 & 0.0069 & & & 7891 & $10 \%$ & $13 \%$ \\
\hline
\end{tabular}

Table 4:

Top Ten Substitutes - Emissions

\begin{tabular}{|c|c|c|c|c|c|c|}
\hline \multirow[b]{2}{*}{ Unit Name } & \multicolumn{2}{|c|}{ Offset SO2 } & \multicolumn{2}{|c|}{ Offset Nox } & \multicolumn{2}{|c|}{ Offset $\mathrm{CO} 2$} \\
\hline & lbs/MWH wind & Pct of Total & Ibs/MWH wind & Pct of Total & Ibs/MWH wind & Pct of Total \\
\hline Big Brown Unit 2 & -1.00 & $31.6 \%$ & -0.08 & $7.7 \%$ & -121.11 & $7.7 \%$ \\
\hline Forney & 0.00 & $0.0 \%$ & -0.01 & $1.1 \%$ & -36.89 & $2.3 \%$ \\
\hline Big Brown Unit 1 & -0.74 & $23.5 \%$ & -0.06 & $5.7 \%$ & -90.03 & $5.7 \%$ \\
\hline Permian Basin Unit 6 & -0.02 & $0.6 \%$ & -0.07 & $6.8 \%$ & -47.96 & $3.0 \%$ \\
\hline Tenaska Gateway & 0.00 & $0.0 \%$ & -0.01 & $0.6 \%$ & -26.96 & $1.7 \%$ \\
\hline Fayette Power Unit 2 & -0.17 & $5.3 \%$ & -0.06 & $5.9 \%$ & -68.13 & $4.3 \%$ \\
\hline Stryker Creek Unit 2 & 0.00 & $0.1 \%$ & -0.03 & $2.7 \%$ & -44.77 & $2.8 \%$ \\
\hline Kiamichi Power & 0.00 & $0.0 \%$ & -0.01 & $0.7 \%$ & -26.32 & $1.7 \%$ \\
\hline Fayette Power Unit 1 & -0.13 & $4.1 \%$ & -0.05 & $4.6 \%$ & -52.46 & $3.3 \%$ \\
\hline Monticello Unit 1 & -0.24 & $7.7 \%$ & -0.04 & $3.9 \%$ & -53.01 & $3.4 \%$ \\
\hline Top Ten Total & -2.29 & $73 \%$ & -0.42 & $40 \%$ & -568 & $36 \%$ \\
\hline
\end{tabular}

Table 5:

Market Substitution

\begin{tabular}{lccccc}
\multicolumn{1}{c}{ Offset Power } & Standard & \multicolumn{2}{c}{ Capacity } & Total Market \\
\multicolumn{1}{c}{ Units } & Per 1 MWH Wind & Error & MW & Pct of Total & Production \\
\hline Top 10 & -0.339 & 0.007 & 8295 & $10 \%$ & $13 \%$ \\
Top 50 & -0.807 & 0.012 & 33289 & $40 \%$ & $46 \%$ \\
Top 100 & -0.984 & 0.014 & 54307 & $66 \%$ & $76 \%$ \\
\hline All Units & -1.006 & 0.015 & 82567 & $100 \%$ & $100 \%$
\end{tabular}


Table 6:

Market Emissions

\begin{tabular}{|c|c|c|c|c|c|c|}
\hline \multirow[b]{2}{*}{ Units } & \multicolumn{2}{|c|}{ Offset SO2 } & \multicolumn{2}{|c|}{ Offset Nox } & \multicolumn{2}{|c|}{ Offset $\mathrm{CO} 2$} \\
\hline & Ibs/MWH wind & Pct of Total & $\mathrm{lbs} / \mathrm{MWH}$ wind & Pct of Total & Ibs/MWH wind & Pct of Total \\
\hline Top 10 & -2.29 & $73 \%$ & -0.42 & $40 \%$ & -568 & $36 \%$ \\
\hline Top 50 & -2.98 & $95 \%$ & -0.83 & $79 \%$ & -1239 & $79 \%$ \\
\hline Top 100 & -3.14 & $100 \%$ & -1.01 & $96 \%$ & -1513 & $96 \%$ \\
\hline All Units & -3.15 & $100 \%$ & -1.05 & $100 \%$ & -1572 & $100 \%$ \\
\hline
\end{tabular}

Table 7:

Power Offsets by Fuel

\begin{tabular}{ccccccc} 
& Offset Power & Standard & Offset Power as & \multicolumn{2}{c}{ Capacity } & Total Market \\
\cline { 5 - 6 } Fuel & MWH/MWH Wind & Error & Percent of Production & MW & Pct of Total nnn & Production \\
\hline Gas & -0.718 & 0.023 & $-3.0 \%$ & 58406 & $71 \%$ & $47 \%$ \\
Coal & -0.286 & 0.006 & $-1.5 \%$ & 17321 & $21 \%$ & $38 \%$ \\
Nuclear & -0.008 & 0.001 & $-0.1 \%$ & 5203 & $6 \%$ & $13 \%$ \\
Hydro & -0.002 & 0.001 & $-1.6 \%$ & 643 & $0.8 \%$ & $0.2 \%$ \\
Imports & 0.007 & 0.004 & $1.4 \%$ & 828 & $1.0 \%$ & $1.0 \%$ \\
Other & -0.001 & 0.0002 & $-0.4 \%$ & 166 & $0.2 \%$ & $0.4 \%$ \\
\hline Market & -1.006 & 0.035 & $-2.0 \%$ & 82567 & $100 \%$ & $100 \%$
\end{tabular}

Table 8:

Emissions Offsets by Fuel

\begin{tabular}{|c|c|c|c|c|c|c|}
\hline \multirow[b]{2}{*}{ Fuel } & \multicolumn{2}{|c|}{ Offset SO2 } & \multicolumn{2}{|c|}{ Offset Nox } & \multicolumn{2}{|c|}{ Offset CO2 } \\
\hline & Ibs/MWH wind & Pct of Total & Ibs/MWH wind & Pct of Total & Ibs/MWH wind & Pct of Total \\
\hline Gas & -0.10 & $3 \%$ & -0.58 & $55 \%$ & -915.053 & $58 \%$ \\
\hline Coal & -3.05 & $97 \%$ & -0.47 & $44 \%$ & -656 & $42 \%$ \\
\hline Nuclear & 0.00 & $0 \%$ & 0.00 & $0 \%$ & 0 & $0 \%$ \\
\hline Hydro & 0.00 & $0 \%$ & 0.00 & $0 \%$ & 0 & $0 \%$ \\
\hline Imports & 0.00 & $0 \%$ & 0.00 & $0 \%$ & 0 & $0 \%$ \\
\hline Other & 0.00 & $0 \%$ & 0.00 & $0 \%$ & -2 & $0 \%$ \\
\hline Market Total & -3.15 & $100 \%$ & -1.05 & $100 \%$ & -1572 & $100 \%$ \\
\hline
\end{tabular}


Table 9:

Offsets 2005-2007

\begin{tabular}{lr|c|c|}
\multicolumn{1}{c}{} & \multicolumn{1}{c}{$\begin{array}{c}\text { Tons } \\
\text { Offset }\end{array}$} & \multicolumn{1}{c}{$\begin{array}{c}\text { Percent of } \\
\text { Total } \\
\text { Emissions }\end{array}$} & \multicolumn{1}{c}{$\begin{array}{c}\text { Percent } \\
\text { Wind } \\
\text { Production }\end{array}$} \\
$\mathrm{SO}_{2}$ & 18,277 & $2.12 \%$ & \\
$\mathrm{NO}_{x}$ & 6,119 & $2.14 \%$ & $1.94 \%$ \\
$\mathrm{CO}_{2}$ & $9,122,606$ & $2.04 \%$ & \\
\cline { 2 - 4 } & & &
\end{tabular}

Table 10:

Pollutant Values

\begin{tabular}{cccc} 
& \multicolumn{3}{c}{$\begin{array}{c}\text { Emission Values } \\
\text { (\$/ton of emissions) }\end{array}$} \\
\cline { 2 - 4 } & Low & Middle & High \\
\hline $\mathrm{SO}_{2}$ & $\$ 200$ & $\$ 433$ & $\$ 700$ \\
$\mathrm{NO}_{x}$ & $\$ 2,000$ & $\$ 5,000$ & $\$ 10,000$ \\
$\mathrm{CO}_{2}$ & $\$ 5$ & $\$ 21$ & $\$ 35$ \\
\hline
\end{tabular}

Table 11:

Offset Values

\begin{tabular}{cccc} 
& \multicolumn{3}{c}{$\begin{array}{c}\text { Offset Values } \\
\text { (\$/MWH of Wind Power) }\end{array}$} \\
\cline { 2 - 4 } & Low & Middle & High \\
\hline $\mathrm{SO}_{2}$ & $\$ 0.32$ & $\$ 0.68$ & $\$ 1.10$ \\
$\mathrm{NO}_{x}$ & $\$ 1.05$ & $\$ 2.63$ & $\$ 5.25$ \\
$\mathrm{CO}_{2}$ & $\$ 3.93$ & $\$ 16.51$ & $\$ 27.51$ \\
\hline \hline Total & $\$ 5.30$ & $\$ 19.81$ & $\$ 33.86$
\end{tabular}




\section{Appendix A}

There is some concern that the date dummies may sweep out important identifying variation in wind power across days which might impact the estimates. As an alternative to including date dummies, I estimate here an alternate specification that controls explicitly for the observable factors of fuel prices and generator outages and also includes month by year dummies to control in part for unobservables. The general results are very similar to the results in the from the specification in the body of the paper.

As in the main paper, this specification will include elements of the firms' information set, $\Omega_{t-\tau}$, which they will use when making their decisions 2 hours prior to production. Lagged and comptemporanous wind, demand, temperature, and congestion information are included in the same way as before as is the operating state of each generator on the grid. However, in place of day by year dummies, daily observed controls and month by year dummies are included.

The daily observed controls include the daily spot price for natural gas and the daily maintenance status of all 350 generators on the grid. Since natural gas turbines are almost always the price setting units on the grid, gas price is important, both for cost considerations and for predicting profitability. The outage status of other generators on the grid is included as it will reshape the cost profile of competing generators. I assume maintenance periods are exogenous, in the sense that firms do not strategically withhold power by putting some units out for 'maintenance'. Although strategic maintenance decisions have been a concern in some electricity markets such as California, market monitors in Texas have not found evidence of such behavior (Potomac 2007). The outage vector also provides a simple way of incorporating new facilities into the model. New 
generating facilities are simply on a "maintenance outage" until they enter the market.

Month dummies by year, are also include in the specification. Since retail prices are not constant over the sample, the dummies help control for changes in the demand function due to the possibility of retail contracts with prices that update monthly. Dummies also play a role in controlling for the unobserved financial position of the firm in the bilateral markets. Even though a firm's forward contract position does not constrain the firm's operation decisions (as it can always purchase wholesale power market to satisfy its position) it can influence its incentives to exercise market power. In a perfectly competitive setting, the financial position of a firm is irrelevant. However, if firms can exercise market power, their position as net-sellers or net-buyers in the market will influence their incentives to use market power to their advantage. The dummies will capture monthly variation in a firm's long-term forward contracts, as it affects the operation of its generators.

To summarize, the estimation equation will include contemporaneous wind power production in quadratic expansion, 4 contemporaneous controls (7 including quadratic expansion terms), 92 lagged controls (161 including quadratic expansion terms), 332 dummies for the lagged operating state of generators, 332 dummies for generator-specific daily outages, the current and past day's gas prices (4 variable including quadratic expansion terms), and 24 month/year dummies. This set of variables (see table A2), while not entirely exhaustive, provides a rich set of controls for incentives that a generator may face which may also be correlated with wind power production.

The estimation procedure will be performed separately for each generator on the grid to allow for complete flexibility across generator characteristics. The wide variety in 
generator technologies and vintages imply generators face vastly different cost structures and production incentives.

The estimation proceeds for each of the 332 generators, using OLS with the flexible polynomial expansion of the variables:

$$
q_{i t}=\beta_{i 0}+\beta_{i 1} \text { Wind }_{t}+\beta_{i 2} \text { Wind }_{t}^{2}+Z_{t} \gamma_{i}+D_{t} \alpha_{i}+\epsilon_{i t}
$$

where Wind $_{t}$ is the amount of wind power produced in the current 15-minute time period, $Z_{t}$ are the contemporaneous and lagged control variables in quadratic expansion, and $D_{t}$ are the operating, outage, and month/year dummies.

Days where the generator is experiencing a scheduled or emergency maintenance outage are excluded from the analysis as I assume that these outages are not a strategic decision, but would have been necessary, regardless of the level of wind power. Excluding outages is important as most scheduled outages occur in the spring and the fall when demand is low, but wind power production is high.

Since the information set is common across the estimating equations there is no efficiency advantage to using seemingly unrelated regression techniques. Also, although we would expect the sum of the marginal impacts to sum to approximately one, I do not impose constraints which would require $1 \mathrm{MWh}$ of wind power to offset $1 \mathrm{MWh}$ of conventional generation. Since wind power is not produced near demand centers it could be that the offsets could be less than one-to-one due to transmission line losses, if wind power is a 
substitute for generators which are closer to demand centers.

Tables A2 through A10 show the results in the same format as previously delineated. The parameter estimates for the top ten substituting generators are statistically different from the main specification, but nine of the top ten generators are still in the top ten with one substitution from a generator that was ranked slightly lower in the main specification. Looking at the breakdown of substitution by fuel type in table A6 shows several differences from the prior specification. First, total power offsets are $-1.095 \mathrm{MWh}$ for each MWh of wind power production which is different from the one to one relationship that we would expect. The estimate of offset power is also statistically different from -1.00 at the 95\% confidence level. This "over" reduction shows up as more significant offsets from both gas and coal as compared to the main specification. This will imply slightly higher estimated emission offsets than we say previously. The estimates from the other fuels types are roughly equivalent to the main specification.

Comparing grid wide emissions offsets per MWh of wind power in this specification in (table A7) with the main specification (table 8) shows that the alternative specification estimates higher offsets by about $10 \%$ for $\mathrm{SO}_{2}, \mathrm{NO}_{x}$, and $\mathrm{CO}_{2}$. This leads to a offset value in table A10 of $\$ 21.38$ as compared to $\$ 19.81$ in table 11 for the main specification.

While the using daily controls rather than date dummies does produce statistically different results the economic interpretation of the results is largely the same. 


\section{Table A1: \\ Estimation Variables}

Independent Variables

Contemporaneous Variables

Wind $_{t}$

Wind $_{t}^{2}$

Demand $_{t}$

Demand $_{t}^{2}$

Temperature

Temperature $_{t}^{2}$

Congest $_{t}$

Lagged Variables

Operate $1_{t-9}$

Operate $332_{t-9}$

Wind $_{t-9}$

Wind $_{t-9}^{2}$

Demand $_{t-9}$

Demand $_{t-9}^{2}$

Temperature $_{t-9}$

Temperature $_{t-9}^{2}$

Congest $_{t-9}$

$\cdots$

...

Wind $_{t-100}$

Wind $_{t-100}^{2}$

Demand $_{t-100}$

Demand $_{t-100}^{2}$

Temperature $_{t-100}$

Temperature $_{t-100}^{2}$

Congest $_{t-100}$

Description

Wind power production for current period (MWH)

Square of wind power production for current period

System demand for current period (MWH)

Square of system demand for current period (MWH)

Average system wide temperature for current period

Square of average system wide temperature for current period

Indicator for inter-zonal congestion

Operating indicator for generator 1 lagged $2 \mathrm{hrs}$

Operating indicator for generator 332 lagged $2 \mathrm{hrs}$

Wind power production lagged 2 hrs (9 periods)

Square of wind power production lagged $2 \mathrm{hrs}$ (9 periods)

System demand lagged 2 hrs ( 9 periods)

Square of system demand lagged 2 hrs (9 periods)

Average system wide temperature lagged 2 hrs (9 periods)

Square of average system wide temperature lagged $2 \mathrm{hrs}$ (9 periods)

Indicator for inter-zonal congestion lagged 2 hrs (9 periods)

...

Wind power production lagged $25 \mathrm{hrs}$ (100 periods)

Square of wind power production lagged $25 \mathrm{hrs}$ (100 periods)

System demand lagged $25 \mathrm{hrs}$ (100 periods)

Square of system demand lagged $25 \mathrm{hrs}$ (100 periods)

Average system wide temperature lagged $25 \mathrm{hrs}$ (100 periods)

Square of average system wide temperature lagged $25 \mathrm{hrs}$ (100 periods)

Indicator for inter-zonal congestion lagged $25 \mathrm{hrs}$ (100 periods)

Daily Variables

Outage 1

Outage indicator for state of generator 1

Outage 332

...

Outage indicator for state of generator 332

Daily spot price of natural gas

Square of daily spot price of natural gas 
Dummies

Month/Year Month by year dummies

Table A2:

Top Ten Substitutes - Production

\begin{tabular}{lcccccccc} 
& Offset Power & Standard & Fuel & & \multicolumn{2}{c}{ Capacity } & Total Market \\
\cline { 6 - 7 } \multicolumn{1}{c}{ Unit Name } & Per 1 MWH Wind & Error & Type & Technology & & Unit & Pct of Total & Production \\
\hline Big Brown Unit 2 & -0.051 & 0.0014 & Coal & Steam Turbine & 598 & $0.8 \%$ & $1.4 \%$ \\
Kiamichi Power & -0.040 & 0.0038 & Gas & Combine Cycle & 1151 & $1.6 \%$ & $1.8 \%$ \\
Fayette Power Unit 2 & -0.038 & 0.0014 & Coal & Steam Turbine & 608 & $0.8 \%$ & $1.3 \%$ \\
Big Brown Unit 1 & -0.036 & 0.0011 & Coal & Steam Turbine & 597 & $0.8 \%$ & $1.5 \%$ \\
Forney & -0.033 & 0.0057 & Gas & Combine Cycle & 1770 & $2.3 \%$ & $2.6 \%$ \\
Fayette Power Unit 1 & -0.032 & 0.0013 & Coal & Steam Turbine & 616 & $0.8 \%$ & $1.3 \%$ \\
Pemian Basin Unit 6 & -0.031 & 0.0017 & Gas & Steam Turbine & 523 & $0.6 \%$ & $0.2 \%$ \\
Stryker Creek Unit 2 & -0.029 & 0.0017 & Gas & Steam Turbine & 499 & $0.6 \%$ & $0.2 \%$ \\
Tenaska Gateway & -0.029 & 0.0038 & Gas & Combine Cycle & 978 & $1.1 \%$ & $1.4 \%$ \\
Cedar Bayou Unit 2 & -0.025 & 0.0021 & Gas & Steam Turbine & 745 & $0.9 \%$ & $0.4 \%$ \\
\hline \multicolumn{1}{c}{ Top Ten Total } & -0.34 & 0.0080 & & & & 8085 & $10 \%$ & $12 \%$
\end{tabular}

Table A3:

Top Ten Substitutes - Emissions

\begin{tabular}{|c|c|c|c|c|c|c|c|}
\hline \multirow[b]{2}{*}{ Unit Name } & \multirow{2}{*}{$\begin{array}{l}\text { Fuel } \\
\text { Type }\end{array}$} & \multicolumn{2}{|c|}{ Offset SO2 } & \multicolumn{2}{|c|}{ Offset Nox } & \multicolumn{2}{|c|}{ Offset CO2 } \\
\hline & & $\mathrm{Ibs} / \mathrm{MWH}$ wind & Pct of Total & Ibs/MWH wind & Pct of Total & $\mathrm{Ibs} / \mathrm{MWH}$ wind & Pct of Total \\
\hline Big Brown Unit 2 & Coal & -1.01 & $30.8 \%$ & -0.08 & $7.1 \%$ & -123.07 & $7.3 \%$ \\
\hline Kiamichi Power & Gas & 0.00 & $0.0 \%$ & -0.01 & $0.9 \%$ & -36.97 & $2.2 \%$ \\
\hline Fayette Power Unit 2 & Coal & -0.20 & $6.0 \%$ & -0.07 & $6.3 \%$ & -79.81 & $4.7 \%$ \\
\hline Big Brown Unit 1 & Coal & -0.70 & $21.4 \%$ & -0.06 & $5.0 \%$ & -85.69 & $5.1 \%$ \\
\hline Forney & Gas & 0.00 & $0.0 \%$ & -0.01 & $0.8 \%$ & -29.27 & $1.7 \%$ \\
\hline Fayette Power Unit 1 & Coal & -0.17 & $5.0 \%$ & -0.06 & $5.3 \%$ & -67.33 & $4.0 \%$ \\
\hline Pemian Basin Unit 6 & Gas & -0.02 & $0.5 \%$ & -0.06 & $5.3 \%$ & -41.51 & $2.5 \%$ \\
\hline Stryker Creek Unit 2 & Gas & 0.00 & $0.0 \%$ & -0.03 & $2.4 \%$ & -42.31 & $2.5 \%$ \\
\hline Tenaska Gateway & Gas & 0.00 & $0.0 \%$ & -0.01 & $0.5 \%$ & -22.96 & $1.4 \%$ \\
\hline Cedar Bayou Unit 2 & Gas & 0.00 & $0.0 \%$ & -0.02 & $1.4 \%$ & -34.01 & $2.0 \%$ \\
\hline Top Ten Total & & -2.10 & $64 \%$ & -0.41 & $35 \%$ & -563 & $33 \%$ \\
\hline
\end{tabular}


Table A4:

Market Substitution

\begin{tabular}{lccccc} 
& Offset Power & Standard & \multicolumn{2}{c}{ Capacity } & Total Market \\
\multicolumn{1}{c}{ Units } & Per 1 MWH Wind & Error & MW & Pct of Total & Production \\
\hline Top 10 & -0.344 & 0.009 & 8455 & $10 \%$ & $12 \%$ \\
Top 50 & -0.886 & 0.015 & 34101 & $41 \%$ & $46 \%$ \\
Top 100 & -1.076 & 0.017 & 53889 & $65 \%$ & $78 \%$ \\
\hline All Units & -1.095 & 0.019 & 82603 & $100 \%$ & $100 \%$
\end{tabular}

Table A5:

Market Emissions

\begin{tabular}{|c|c|c|c|c|c|c|}
\hline \multirow[b]{2}{*}{ Units } & \multicolumn{2}{|c|}{ Offset SO2 } & \multicolumn{2}{|c|}{ Offset Nox } & \multicolumn{2}{|c|}{ Offset $\mathrm{CO} 2$} \\
\hline & Ibs/MWH wind & Pct of Total & Ibs/MWH wind & Pct of Total & Ibs/MWH wind & Pct of Total \\
\hline Top 10 & -2.10 & $64 \%$ & -0.41 & $35 \%$ & -563 & $33 \%$ \\
\hline Top 50 & -3.04 & $93 \%$ & -0.93 & $80 \%$ & -1334 & $79 \%$ \\
\hline Top 100 & -3.28 & $100 \%$ & -1.11 & $96 \%$ & -1632 & $96 \%$ \\
\hline All Units & -3.29 & $100 \%$ & -1.16 & $100 \%$ & -1692 & $100 \%$ \\
\hline
\end{tabular}

Table A6:

Power Offsets by Fuel

\begin{tabular}{|c|c|c|c|c|c|c|}
\hline \multirow[b]{2}{*}{ Fuel } & \multirow{2}{*}{$\begin{array}{c}\text { Offset Power } \\
\text { MWH/MWH Wind }\end{array}$} & \multirow{2}{*}{$\begin{array}{l}\text { Standard } \\
\text { Error }\end{array}$} & \multirow{2}{*}{$\begin{array}{c}\text { Offset Power as } \\
\text { Percent of Production }\end{array}$} & \multicolumn{2}{|c|}{ Capacity } & \multirow{2}{*}{$\begin{array}{l}\text { Total Market } \\
\text { Production }\end{array}$} \\
\hline & & & & MW & Pct of Total & \\
\hline All Gas & -0.781 & 0.017 & $-3.2 \%$ & 58406 & $71 \%$ & $47 \%$ \\
\hline Coal & -0.309 & 0.031 & $-1.6 \%$ & 17321 & $21 \%$ & $38 \%$ \\
\hline Nuclear & -0.006 & 0.003 & $-0.1 \%$ & 5203 & $6 \%$ & $13 \%$ \\
\hline Hydro & -0.001 & 0.003 & $-1.3 \%$ & 643 & $0.8 \%$ & $0.2 \%$ \\
\hline Imports & 0.003 & 0.005 & $0.6 \%$ & 864 & $1.0 \%$ & $1.0 \%$ \\
\hline Other & -0.001 & 0.0002 & $-0.3 \%$ & 166 & $0.2 \%$ & $0.4 \%$ \\
\hline Market & -1.095 & 0.036 & $-2.1 \%$ & 82603 & $100 \%$ & $100 \%$ \\
\hline
\end{tabular}

Table A7:

Emissions Offsets by Fuel 


\begin{tabular}{|c|c|c|c|c|c|c|}
\hline \multirow[b]{2}{*}{ Fuel } & \multicolumn{2}{|c|}{ Offset SO2 } & \multicolumn{2}{|c|}{ Offset Nox } & \multicolumn{2}{|c|}{ Offset $\mathrm{CO} 2$} \\
\hline & Ibs/MWH wind & Pct of Total & $\mathrm{lbs} / \mathrm{MWH}$ wind & Pct of Total & Ibs/MWH wind & Pct of Total \\
\hline All Gas & -0.10 & $3 \%$ & -0.63 & $54 \%$ & -984.248 & $58 \%$ \\
\hline Coal & -3.18 & $97 \%$ & -0.53 & $46 \%$ & -707 & $42 \%$ \\
\hline Nuclear & 0.00 & $0 \%$ & 0.00 & $0 \%$ & 0 & $0 \%$ \\
\hline Hydro & 0.00 & $0 \%$ & 0.00 & $0 \%$ & 0 & $0 \%$ \\
\hline Imports & 0.00 & $0 \%$ & 0.00 & $0 \%$ & 0 & $0 \%$ \\
\hline Other & 0.00 & $0 \%$ & 0.00 & $0 \%$ & -1 & $0 \%$ \\
\hline Market & -3.29 & $100 \%$ & -1.16 & $100 \%$ & -1692 & $100 \%$ \\
\hline
\end{tabular}

Table A8:

Offsets 2005-2007

\begin{tabular}{|c|c|c|c|}
\hline & $\begin{array}{l}\text { Tons } \\
\text { Offset }\end{array}$ & $\begin{array}{c}\text { Percent of } \\
\text { Total } \\
\text { Emissions }\end{array}$ & $\begin{array}{c}\text { Percent } \\
\text { Wind } \\
\text { Production }\end{array}$ \\
\hline $\mathrm{SO}_{2}$ & 19,059 & $2.21 \%$ & \\
\hline$O_{x}$ & 6,728 & $2.35 \%$ & $1.90 \%$ \\
\hline $\mathrm{CO}_{2}$ & $9,818,921$ & $2.19 \%$ & \\
\hline
\end{tabular}

Table A9:

Pollutant Values

\begin{tabular}{lccc} 
& \multicolumn{3}{c}{$\begin{array}{c}\text { Pollutant Values } \\
\text { (\$/ton of pollutant) }\end{array}$} \\
\cline { 2 - 4 } & Low & Middle & High \\
\hline $\mathrm{SO}_{2}$ & $\$ 200$ & $\$ 433$ & $\$ 700$ \\
$\mathrm{NO}_{\mathrm{x}}$ & $\$ 2,000$ & $\$ 5,000$ & $\$ 10,000$ \\
$\mathrm{CO}_{2}$ & $\$ 5$ & $\$ 21$ & $\$ 35$ \\
\hline
\end{tabular}

Table A10:

Offset Values 


\begin{tabular}{cccc} 
& \multicolumn{3}{c}{$\begin{array}{c}\text { Uttset Values } \\
(\$ / \mathrm{MWH} \text { of Wind Power })\end{array}$} \\
\cline { 2 - 4 } & Low & Middle & High \\
\hline $\mathrm{SO}_{2}$ & $\$ 0.33$ & $\$ 0.71$ & $\$ 1.15$ \\
$\mathrm{NO}_{\mathrm{x}}$ & $\$ 1.16$ & $\$ 2.90$ & $\$ 5.80$ \\
$\mathrm{CO}_{2}$ & $\$ 4.23$ & $\$ 17.77$ & $\$ 29.61$ \\
\hline \hline Total & $\$ 5.72$ & $\$ 21.38$ & $\$ 36.56$
\end{tabular}

